\title{
GESTÃO PROCESSUAL FLEXÍVEL, COLABORATIVA E PROPORCIONAL: CENÁRIOS PARA IMPLEMENTAÇÃO DAS NOVAS TENDÊNCIAS NO CPC/2015
}

\author{
FLEXIBLE, COLLABORATIVEANDPROPORTIONALPROCEDURAL \\ MANAGEMENT: SCENARIOS FOR IMPLEMENTATION OF THE \\ 2015 CPC'S NEW TRENDS
}

ÉRICO ANDRADE*

\begin{abstract}
RESUMO
O ponto de partida do estudo é a análise, no âmbito do direito comparado, das linhas evolutivas mais modernas do processo civil, a partir da qual se constata que as atuais reformas têm buscado atuar as linhas da gestão processual flexível, proporcional e colaborativa. Parte-se, então, para verificação se estas linhas mais atuais da evolução do processo civil comparado podem ser encontradas no CPC/2015, especialmente da gestão processual colaborativa entre partes e juiz, para buscar as melhores formas de atuação procedimental para a solução do caso concreto. Chega-se, com isso, ao cerne do trabalho que é apresentar as novas perspectivas da gestão processual no CPC/2015, no âmbito de atuação do princípio da colaboração entre juiz e partes acolhidos na norma fundamental do art. $6^{\circ}$ do CPC/2015.
\end{abstract}

PALAVRAS-CHAVE: Gestão Processual. Atuação da flexibilidade, proporcionalidade e colaboração no CPC/2015. Gestão Processual Colaborativa no CPC/2015.

\begin{abstract}
The starting point of this research is the analysis, in the scope of the comparative law, of the most modern evolutionary lines of the Civil Procedure, from which it is established that the current renovations are seeking to act the flexible, proportional and collaborative procedural management lines. We then depart to the verification if those latest strands of the evolution of the compared civil procedure can be found on the 2015 CPC, especially of the collaborative procedural management between parts and judge, to pursue the best ways of procedural performance for the resolution of the specific case. Arriving to the heart of this study, the new perspectives of procedural management in the 2015 CPC, in the acting area of the collaboration between judge and parts, welcomed in the fundamental rule of article 6 of the 2015 CPC.
\end{abstract}

KEYWORDS: Procedural Management. Performance of flexibility, proportionality and collaboration in the 2015 CPC. Use for Collaborative Procedural in the 2015 CPC.

SUMÁRIO: 1. INTRODUÇÃO: AS NOVAS TENDÊNCIAS DA GESTÃO PROCESSUAL 2. PERSPECTIVA COMPARADA: TENDÊNCIAS EVOLUTIVAS DO PROCESSO CIVIL EUROPEU PERMEADAS PELA GESTÃO PROCESSUAL FLEXÍVEL, PROPORCIONAL E COLABORATIVA 3. FLEXIBILIDADE, PROPORCIONALIDADE E COLABORAÇÃO NO CPC/2015: AMBIENTE PARA GESTÃO PROCESSUAL COLABORATIVA 4. AS NOVAS PERSPECTIVAS DA GESTÃO PROCESSUAL

\footnotetext{
* Professor Adjunto de Processo Civil da Graduação e Pós-graduação da UFMG. Doutor em Direito Processual Civil pela UFMG/ "Università degli Studi di Milano”. Mestre em Direito Administrativo pela UFMG. E-mail: ericoandrade@ufmg.br.
} 


\section{NO CPC/2015 5. BREVES INDICAÇÕES CONCLUSIVAS.} REFERÊNCIAS.

\section{INTRODUÇÃO: AS NOVAS TENDÊNCIAS DA GESTÃO PRO- CESSUAL}

Tema que tem atraído a atenção da doutrina estrangeira, com destaque para as experiências inglesa e francesa, ${ }^{1}$ e mesmo da doutrina brasileira, ${ }^{2}$ é o da "gestão processual" ou "gerenciamento" do processo, em que o juiz assume o papel de "gestor" do processo, para organizar e conduzir a marcha processual, em sede de procedimento flexível ou adaptável segundo a complexidade do caso concreto, o que pode permitir distribuição mais adequada dos recursos judiciais entre todos os processos em curso, na busca de atuação mais efetiva da duração razoável do processo. ${ }^{3}$

A tal cenário de gestão processual flexível, permeada pela proporcionalidade na distribuição dos recursos judiciais, para permitir maior efetividade da garantia da duração razoável do processo, ${ }^{4}$ tem-se agregado a perspectiva da colaboração, de modo a permitir até mesmo a identificação de importante tendência atual do processo civil europeu, como destacou recentemente Michele Angelo Lupoi, ao apontar que flexibilidade, colaboração

1 Cf. DE CRISTOFARO, Marco. Case management e riforma del processo civile, tra effettività della giurisdizione e diritto costituzionale al giusto processo. Rivista di Diritto Processuale, Padova: Cedam, anno LXV, n. 2, p. 283, marzo-aprile/2010.

2 Cf., por exemplo, ANDRADE, Érico. As novas perspectivas do gerenciamento e da “contratualização” do processo. Revista de Processo, São Paulo, RT, vol. 193, p. 167-199, mar/2011. As discussões no direito brasileiro se intensificaram especialmente no ambiente de reforma do processo civil instaurado a partir do final de 2009 , com a instituição de Comissão de Juristas, pelo Senado Federal, para elaborar o Anteprojeto de Novo Código de Processo Civil (Ato do Presidente $n^{\circ} 379$, de 30 de setembro de 2009), e que veio a desaguar na publicação do novo Código em março de 2015.

3 BIAVATI, Paolo. Flessibilità, semplifcazione e gestione del processo civile: la prospettiva italiana. In: ZUFELATO, Camilo; BONATO, Giovanni; SICA; Heitor Vitor Mendonça; CINTRA, Lia Carolina Batista (Coord). I Colóquio Brasil-Itália de Direito Processual Civil, Salvador, Editora Jus Podium, 2016, p. 210, indica que o mecanismo do processo flexível compõe a chamada gestão processual por parte do juiz, como um dos seus instrumentos, e que permite atuar o princípio da duração razoável: “A me sembra che l'espressione case management alluda a due aspetti. Il primo e più intuitivo richiama la direzione del processo, e sotto questo profilo non ha alcuna speciale carica innovativa. Il secondo, che va letto insieme al primo, richiama la regionevole durata del processo e un corretto impiego delle scarse risorse giurisdizionali. Il giudice case manager non è solo un abile organizzatore del singolo processo, ma piuttosto un attento analista del rapporto fra la complessità di quel caso, il bempo che egli vi può dedicare e gli altri procedimenti che gli sono affidati. Questo giudice (a cui non dovrebbero mancare competenze tipiche dell'organizzazione aziendale) sa governare al meglio non solo la singola causa, ma anche l'equilibrio fra quel processo e il complesso dell'attività giurisdizionale de un dato organo".

4 Cf. THEODORO JÚNIOR, Humberto; ANDRADE, Érico. Impactos da Constituição Federal na evolução do processo civil. In: MORAES, Guilherme Peña de (Org.). 30 Anos da Constituição Federal e o Direito Brasileiro. Rio de Janeiro: Forense-Gen, 2018, p. 337. 
e proporcionalidade são as palavras de ordem que se encontram subjacentes às atuais reformais processuais de diversos sistemas de justiça civil. ${ }^{5}$

No direito brasileiro, entende-se que o CPC/2015 caminha na mesma direção dessa atual tendência, ao adotar expressamente, no âmbito de suas normas fundamentais, os princípios da duração razoável e eficiência, que estabelecem a necessidade de proporcionalidade no uso dos recursos judiciais $\left(\right.$ arts. $4^{\circ}$ e $8^{\circ}$ ), tudo permeado pela colaboração entre juiz e partes (art. $6^{\circ}$ ), integrados na busca de maior eficiência da atuação jurisdicional para solucionar as crises de direito material (arts. $6^{\circ}$ e $8^{\circ}$ ).

Além disso, o CPC/2015 também prevê a inserção do juiz como "gestor" do processo (art. 139) e se abre para vários mecanismos de flexibilização procedimental, como o uso de meios consensuais para solução de conflitos jurídicos, dentro e fora do processo (art. $3^{\circ}, \mathbb{S} \mathbb{S} 2^{\circ}$ e $3^{\circ}$ ), e, ainda, apresenta percursos procedimentais diversificados para solução das crises de direito material. ${ }^{6}$

Registre-se que a pesquisa ora realizada, na vertente dogmático-jurídica, visa a analisar os elementos internos do ordenamento jurídico e quanto ao tipo, se trata de pesquisa bibliográfica e comparativa, pois neste último caso se utilizou de estudos comparados; e, quanto à técnica, de levantamento de dados bibliográficos nacionais e estrangeiros. ${ }^{7}$

A proposta deste trabalho é apresentar, na linha de indicação de possíveis tendências para o futuro do processo civil, sob a perspectiva comparada, breve analise da abertura normativa e principiológica do CPC/2015 para a flexibilidade, proporcionalidade e colaboração, com indicação, por exemplo, do uso dos negócios jurídicos processuais como importante ferramenta para contribuir para a gestão processual mais eficiente.

\section{PERSPECTIVA COMPARADA: TENDÊNCIAS EVOLUTIVAS DO PROCESSO CIVIL EUROPEU PERMEADAS PELA GESTÃO PROCESSUAL FLEXÍVEL, PROPORCIONAL E COLABORATIVA}

A doutrina italiana ${ }^{8}$ tem perquirido as tendências evolutivas atuais do processo civil, diante da necessidade de se buscar uma justiça mais eficiente

5 LUPOI, Michele Angelo. Tra flessibilità e semplificazione - Un embrione di case management all'italiana? Bologna: Bononia University Press, 2018, p. 66: "Flessibilità, collaborazione, proporzionalità sono dunque le parole d'ordine sottese alle esperienze riformatrici dei sistemi civili di amministrazione della giustizia in alcuni importanti ordinamenti con linee evolutive che, nel rispetto delle differenti tradizioni, presentano rilevanti profili di assonanza".

6 Cf. THEODORO JÚNIOR, Humberto; ANDRADE, Érico. Impactos da Constituição Federal na evolução do processo civil. In: MORAES, Guilherme Peña de (Org.).30 Anos da Constituição Federal e o Direito Brasileiro. Rio de Janeiro: Forense-Gen, 2018, p. 351-353.

7 GUSTIN, Miracy B. S.; e DIAS, Maria Tereza Fonseca. (Re)pensando a pesquisa jurídica. $4^{a}$ ed. Belo Horizonte: Editora DelRey, 2015.

8 Registre-se que o cenário comparado que ora se apresenta é baseado principalmente nas 
em contraste com o cenário de crise econômica que atinge vários países, com severas restrições orçamentárias para a administração da justiça, ${ }^{9}$ considerando que, cada vez mais, a concepção de jurisdição como poder estatal vem sendo deixada de lado, entendendo-se a justiça como serviço público atuante em favor do indivíduo e da coletividade, ${ }^{10}$ donde a necessidade de simplificar as regras processuais para permitir maior acesso ao serviço justiça. ${ }^{11}$

Nesse contexto, tem-se detectado nas atuais tendências evolutivas do processo civil dos países europeus, de tradições jurídicas diversas, a adoção de estratégias comuns para abreviar a duração do processo e garantir tutela jurisdicional mais eficiente dos direitos, com redução dos custos, ${ }^{12}$ envolvendo valorização da gestão processual pelo juiz, na organização do procedimento e das atividades das partes, sendo que as tendências mais avançadas destacam cada vez mais o aspecto colaborativo: a atividade de gestão processual pelo juiz não deve ser realizada em confronto com as partes, de forma unilateral, mas sim de forma colaborativa entre partes e juiz. ${ }^{13}$

contribuições trazidas por Michele Angelo Lupoi em sua recente obra publicada sobre a temática: Tra flessibilità e semplificazione - Un embrione di case management all'italiana? Bologna: Bononia University Press, 2018.

9 LUPOI, Michele Angelo. Tra flessibilità e semplificazione - Un embrione di case management all'italiana? Bologna: Bononia University Press, 2018, p. 6.

10 Cf., por exemplo, CAPONI, Remo. Il principio di proporzionalità nella giustizia civile: prime note sistematiche. Rivista Trimestrale di Diritto e Procedura Civile, Milano, Giuffrè Editore, v. LXV, 2011, n. 2, pp. 391/392: "Dire che lo scopo del processo civile è la giusta compozione della controversia entro un termine ragionevole non significa 'indossare un vestito buono per tutte le stagioni', ma implica di compiere una scelta piuttosto determinata. Essa entra in tensione critica con la concezione che vede nell'amministrazione della giustizia una funzione essenziale propria dello Stato moderno al servizio della attuazione della 'volontà della legge', con le caratteristiche della relativa incontestabilità sul piano del diritto sostanziale e nel corso dei futuri processi. Questa seconda concezione si rende interprete di una tradizione alta e ricca di prestigio, ma relega piuttosto sullo sfondo l'utilità che gli individui, in quanto parti del processo, ricavano dall'esercizio della giurisdizione. Lo scopo del processo tende ad essere colto attualmente, piuttosto, nell'attuazione dei diritti soggettivi dei privati. Se questo è vero, in primo piano si profila l'utilità che gli individui si ripromettono di conseguire nel momento in cui intraprendono (o si difendono in) un processo. Di conseguenza, la giurisdizione non è da concepire solo come una funzione dello Stato moderno diretta all'attuazione del diritto nel caso concreto, ma anche - in primo luogo - come servizio pubblico diretto alla composizione delle controversie secondo giustizia (cioè con l'applicazione di criteri di giudizo oggettivi e predeterminati). Dominante in questa prospettiva è proprio l'utilità aspirata da chi agisce (o si difende) in giudizio)".

11 LUPOI, Michele Angelo. Tra flessibilità e semplificazione - Un embrione di case management all'italiana? Bologna: Bononia University Press, 2018, p. 8, destaca o contexto em que se inserem as reformas na justiça civil: "In un'ottica in cui la funzione giurisdizionale viene ormai comunemente considerata non più un'espressione della sovranità dello Stato ma, piuttosto, come un 'servizio' a favore dell'individuo e della collettività, da tempo, a livello internazionale, è, in effetti, avvertita l'esigenza di semplificare le regole processuali, sovente percepite come troppo complesse, e renderle più accessibili all'utente di tale servizio".

12 LUPOI, Michele Angelo. Tra flessibilità e semplificazione - Un embrione di case management all'italiana? Bologna: Bononia University Press, 2018, p. 13.

13 LUPOI, Michele Angelo. Tra flessibilità e semplificazione - Un embrione di case management all'italiana? Bologna: Bononia University Press, 2018, p. 15: "Uno degli elementi che caratterizzano il case management nelle sue interpretazioni più avanzate è la valorizzazione 
Aponta-se, por exemplo, a reforma operada no processo civil francês, focada no papel do juiz como diretor ou gestor do procedimento, com a operacionalização de tal gestão por meio da "contratualização", ou seja, por meio do compartilhamento da atuação gerencial do juiz com as partes, para buscar o melhor funcionamento do procedimento, observando-se que o acordo processual trata não só dos ônus das partes, mas também dos próprios deveres do juiz. ${ }^{14}$

Aliás, nesse sentido, a doutrina francesa indica que é possível vislumbrar a perspectiva contratual decorrente da negociação entre partes e juiz, ainda que o juiz não possa renunciar aos seus poderes, vez que interessa mais de perto, para qualificação do acordo entre partes e juiz como contratual, a negociação, e não apenas a discussão em torno da força obrigatória do acordo processual, vez que a ideia de contrato é apresentada como mecanismo negocial de atuação processual, muito diverso daquele em que o juiz impõe unilateralmente, via decisão judicial, seu entendimento. ${ }^{15}$

A pesquisa comparativa levou, assim, Michele Angelo Lupoi a apresentar pontos comuns nas várias linhas evolutivas mais atuais no âmbito do processo civil, em que se tem valorizado modelo procedimental sob a gestão judicial, exercida em colaboração com as partes, para a organização procedimental e dos tempos processuais, com a recepção explícita dos princípios de flexibilidade e de proporcionalidade como linhas mestras para busca de tutela jurisdicional mais eficiente. ${ }^{16}$

della collaborazione (o, meglio, del confronto) tra giudice e parti, in un'ottica cooperativa e non antagonistica".

14 LUPOI, Michele Angelo. Tra flessibilità e semplificazione - Un embrione di case management all'italiana? Bologna: Bononia University Press, 2018, p. 30: "Al riguardo, si rileva come la riforma francese, pur mettendo al centro il ruolo direttivo del giudice, tramite lo strumento della contrattualizzazione, cerchi di fare condividere alle parti 'la responsabilità dell'iter processuale', per il miglior funzionamento del sistema giustizia. Da questo punto di vista, si osserva che l'accordo processuale non riguarda soltanto gli oneri delle parti, ma anche i doveri del giudice".

15 AMRANI-MEKKI, Soraya. Le temps et le procès civil. Paris: Dalloz, 2002, p. 286: "Il est possible d'y voir un contrat en considérant le contrat, non plus comme une notion fonctionnelle, mais comme un mécanisme. Il y a contrat dès lors qu'il y a un mécanisme contractuel d'élaboration d'une acte: la négociation. La force obligatoire n'est plus un élément constitutif". Nesse sentido a mesma autora aponta, ob. cit., p. 286, que, ainda que o exercício dos poderes do juiz não possa ser objeto de negociação ou de renúncia, trata-se, na realidade, de uso mais inteligente de tais poderes, já que exercitado em ambiente colaborativo com as partes e não impositivamente: "Est encore opposé le fait que le juge tirant son pouvoir de la loi (art. 3 N.C.P.C.) il ne pourrait être objet de négociation. Cependent, il ne renonce pas à ses pouvoirs, au contraire, il les utilise plus intelligemment".

16 LUPOI, Michele Angelo. Tra flessibilità e semplificazione - Un embrione di case management all'italiana? Bologna: Bononia University Press, 2018, p. 54/55: "Le esperienze appena passate in rassegna presentano, come si è visto, notevoli punti comune, confermando che, a livello mondiale, le linee evolutive in ambito processuale valorizzino l'idea di un modello procedimentale improntato all'iniziativa gestionale del giudice e alla collaborazione tra quest'ultimo e le parti nell'organizzazione dei tempi del processo. In questo scenario, in numerose discipline processuali sono stati esplicitamente recepiti i principi di flessibilità e di 
Merece breve detalhamento cada um desses chamados princípiosguia que marcam a linha evolutiva atual do processo civil (flexibilidade, proporcionalidade e colaboração), bem como as respectivas interrelações.

O princípio de flexibilidade em sua concepção mais ampla traduziria a renúncia do ordenamento processual em construir regras procedimentais gerais e abstratas aplicáveis rigidamente para quaisquer controvérsias, optando-se por modelo elástico, no qual o iter procedimental é adaptado e adequado às características do caso concreto. ${ }^{17}$ As atuais tendências indicam, cada vez mais, o abandono de modelos rígidos ou "engessados" de procedimento, construídos em abstrato para grande conjunto de causas, sem possibilidade de adaptação às variantes concretas de cada processo, preferindo-se estruturas elásticas, com modelos diferenciados a partir de peculiaridades de cada causa. ${ }^{18}$

Como exemplo, pode-se citar o modelo francês, em que o procedimento das causas perante o tribunal de grande instance não é definido previamente na legislação processual. São previstos no CPC francês três circuitos procedimentais diversos, denominados circuit long (arts. 763/787, CPC), circuit moyen (art. 761, CPC) e circuit court (art. 760, CPC). ${ }^{19}$

Essa variedade de percursos é estabelecida em função da complexidade da causa, de modo que para o "circuito curto" se encaminham as causas muito simples e que, após a resposta do réu (ou mesmo na sua falta), comportam decisão imediata, sem maiores indagações probatórias; ao "circuito médio" se encaminham as causas que não podem ser decididas de imediato, logo após a defesa do réu, razão pela qual designa-se uma segunda audiência, com troca de articulados defensivos entre as partes, sem necessidade de produção de provas mais complexas, como testemunhal e pericial; e para o "circuito longo" deságuam as causas complexas que demandam instrução probatória, mediante aquisição de provas constituendas. ${ }^{20}$

proporzionalità come linee guida fondamentali per garantire una tutela giurisdizionale più efficiente ed efficace".

17 LUPOI, Michele Angelo. Tra flessibilità e semplificazione - Un embrione di case management all'italiana? Bologna: Bononia University Press, 2018, p. 57: "In particolare, uno di tali principi è quello di flessibilità, alla cui stregua l'ordinamento rinuncia a dettare regole generali e astratte da applicare rigidamente a ogni controversia, preferendo un approccio elastico, nel qual l'iter del processo viene adattato e adeguato alle caratteristiche del caso concreto".

18 LUPOI, Michele Angelo. Tra flessibilità e semplificazione - Un embrione di case management all'italiana? Bologna: Bononia University Press, 2018, p. 58.

19 CADIET, Loic. Les nouvelles tendances de la procédure civile en France. In: BRITO, Rita. (Coord.). Novos Rumos da Justiça Cível: Conferência Internacional, Lisboa, abril 2008. Coimbra: Cejur-Coimbra Editora, 2009, p. 45.

20 DE CRISTOFARO, Marco. Case management e riforma del processo civile, tra effettività della giurisdizione e diritto costituzionale al giusto processo. Rivista di Diritto Processuale, Padova: Cedam, anno LXV, 2010, n. 2, p. 298. No mesmo sentido, cf. CANELLA, Maria Giulia. Gli accordi processuali francesi volti alla "regolamentazione collettiva" del processo civile. Rivista Trimestrale di Diritto e Procedura Civile, Milano, Giuffrè, anno LXIV, 2010, n. 2, p. 557. 
A designação ou escolha do circuito adequado (curto, médio ou longo) ocorre já na primeira audiência, em que o juiz, analisando o processo, e em conjunto com os advogados das partes, define o melhor circuito para a causa concretamente considerada. ${ }^{21}$ Assim, o encaminhamento da causa para um desses circuitos procedimentais ocorre mediante análise prévia do processo pelo juiz, para apurar o grau de complexidade do feito, bem como a necessidade de instrução probatória, ou seja, qual o tipo de prova que é necessário produzir no processo para esclarecimento dos fatos. É propriamente a maior ou menor complexidade do litígio que comanda a orientação procedimental. ${ }^{22}$

Tem-se, por conseguinte, a flexibilização do procedimento: o juiz, de acordo com as necessidades do caso em análise, escolhe o tipo de procedimento mais adequado para aquele feito especificamente considerado. $\mathrm{O}$ procedimento passa a ser adotado "sob medida" e não mais prêt à porter (predefinido abstratamente na legislação processual para todo tipo de situação litigiosa). ${ }^{23}$

Segundo análise comparada feita pela doutrina italiana, em estreita relação com o princípio de flexibilidade procedimental se tem o princípio da proporcionalidade, base para busca da eficiente administração da justiça, a partir do entendimento de que o emprego de recursos públicos e privados para cada causa não deve ser homogêneo, mas proporcional, considerando as características do caso concreto. ${ }^{24}$

Assim, os recursos e o tempo aplicados em cada causa ou processo devem levar em consideração não só as peculiaridades do caso, mas também sua inserção no conjunto de causas em tramitação na justiça, cenário que leva, segundo a doutrina italiana, à compreensão do princípio da duração razoável do processo muito mais voltado para a proporcional distribuição e emprego dos

21 CANELLA, Maria Giulia. Gli accordi processuali francesi volti alla "regolamentazione collettiva" del processo civile. Rivista Trimestrale di Diritto e Procedura Civile, Milano, Giuffrè, anno LXIV, 2010, n. 2, p. 556.

22 CADIET, Loic. Les nouvelles tendances de la procédure civile en France. In: BRITO, Rita. (Coord.). Novos Rumos da Justiça Cível: Conferência Internacional, Lisboa, abril 2008. Coimbra: Cejur-Coimbra Editora, 2009,p. 46: "Implicitement, c'est bien la plus ou moins grande complexité du litige qui commande l'orientation de procédure".

23 CADIET, Loic. Les nouvelles tendances de la procédure civile en France. In: BRITO, Rita. (Coord.). Novos Rumos da Justiça Cível: Conferência Internacional, Lisboa, abril 2008. Coimbra: Cejur-Coimbra Editora, 2009, p. 47: "En vérité, cette réversibilité des techniques procédurales, mises au service d'une rationalisation de la procédure en fonction du degré de complexité de l'affaire, invite à penser les réformes processuelles non plus sur le mode 'prêt à porter' mais sur celui du 'sur-mesure'”.

24 LUPOI, Michele Angelo. Tra flessibilità e semplificazione - Un embrione di case management all'italiana? Bologna: Bononia University Press, 2018, pp. 58/59: "Dall'analisi comparatistica emerge pure che al principio di flessibilità sia associato il principio di proporzionalità, ormai considerato, como si è visto, sia a livello internazionale sia nei singoli orindamenti, come immanente a un sistema efficiente di amministrazione della giustizia. L'idea di base è che l'impegno (pubblico e privato) dedicato alla singola controversia, in termini di costi e tempo, non debba essere omogeneo, bensì proporzionale alla tipologia, all'oggetto e alle caratteristiche della controversia stessa e del caso specifico". 
recursos estatais alocados na justiça ${ }^{25}$ do que medida ou apuração do tempo de duração em cada processo. ${ }^{26}$

Noutras palavras, considerada a massa de processos em curso perante o sistema, a duração razoável vai incidir sobre a forma de gerir a melhor distribuição dos recursos, considerando a aplicação a partir de cada processo, mas sempre relacionada ao conjunto de processos em curso, a fim de se buscar a obtenção da melhor da gestão possível da distribuição dos finitos recursos judiciais. ${ }^{27}$ Com isso, a duração razoável também se coliga com o chamado princípio de proporcionalidade na aplicação dos recursos estatais, extraído da matriz europeia, ${ }^{28}$ e se encarta na nova compreensão da justiça como serviço

25 BIAVATI, Paolo. Osservazioni sulla ragionevole durata del processo di cognizione. Rivista Trimestrale di Diritto e Procedura Civile, Milano, Giuffrè Editore, v. LXVI, 2012, n. 2, p. 478: "A mio avviso, invece, la ragionevole durata è strettamente collegata al problema delle risorse che lo Stato può dedicare al settore della giustizia ed è, perciò, una caratteristica di sistema". Cf. também THEODORO JÚNIOR, Humberto; ANDRADE, Érico. Impactos da Constituição Federal na evolução do processo civil. In: MORAES, Guilherme Peña de (Org.). 30 Anos da Constituição Federal e o Direito Brasileiro. Rio de Janeiro: Forense-Gen, 2018, p. 337.

26 BIAVATI, Paolo. Osservazioni sulla ragionevole durata del processo di cognizione. Rivista Trimestrale di Diritto e Procedura Civile, Milano, Giuffrè Editore, v. LXVI, 2012, n. 2, p. 479: "Se queste premesse sono corrette, si può allora suggerire di intendere la nozione di ragionevole durata non ( $\mathrm{o}$, almeno, non principalmente) como semplice misurazione temporale della lunghezza dei processi, ma come ragionevole impiego di risorse in relazione a quel processo. Ed è in questa chiave che si deve compiere il lavoro, certo imprescindibile, di rilettura delle norme del codice alla luce del precetto di cui all'art. 111 , comma $2^{\circ}$, cost. Ne segue, ancora, se non mi inganno, che il discrimine per una più o meno intensa applicazione del principio della ragionevole durata, in rapporto al diritto di difesa, va collocato in relazione al piano del maggiore o minore impiego di risorse giudiziare che ne viene in gioco".

27 CAPONI, Remo. Il principio di proporzionalità nella giustizia civile: prime note sistematiche. Rivista Trimestrale di Diritto e Procedura Civile, Milano, Giuffrè Editore, v. LXV, 2011, n. 2, pp. 392/393: "Senonché - si anticipa così l'aspetto centrale del ragionamento svolto nel prosieguo - le risorse che il servizio della giustizia può destinare al soddisfacimento di questa esigenza individuale nella singola controversia devono essere bilanciate, nomn tanto con un astratto interesse pubblicistico al buon funzionamento della giurisdizione com funzione statale, bensì con le risorse da riservare al soddisfacimento delle altre esigenze parimenti individuali, di cui sono portatori le parti (attuali o potenziali: quindianche i cittadini) nelle altre controversie indirizzate (o da indirizzare) alla cognizione del giudice statale. In altri termine, poiché le risorse del servizio giustizia sono - e probabilmente saranno sempre (almeno in Italia) - scarse rispetto al fabbisogno, l'effettività del rimedio giurisdizionale nella singola controversia, cioè la congruità della risposta al bisogno individuale di tutela nel singolo caso, è una variabile dipendente dalla necessità di assicurare l'efficienza del sistema giudiziario nel suo complesso, cioè un'allocazione tendenzialmente ottimale delle risorse rispetto ai risultati medi che il servizio giustizia è chiamato a realizzare nella gestione della massa dei processi”.

28 CAPONI, Remo. Il principio di proporzionalità nella giustizia civile: prime note sistematiche. Rivista Trimestrale di Diritto e Procedura Civile, Milano, Giuffrè Editore, v. LXV, 2011, n. 2, pp. 397/398: "Se si intende percorrere con cautela questa strada, entra in gioco per primo uno dei criteri cardine di orientamento nell'esercizio dei pubblici poteri, quel principio di proporzionalità, di matrice europea, di cui devono ancora esplorarsi pienamente le potenzialità assiologiche e deontologiche nel campo della giustizia (più avanti, almeno de iure, è il più generale campo della amministrazione). Esso è efficacemente scolpito nell'art. 1 delle Rules of civil procedure inglesi (1997), laddove si spiega che trattare una causa secondo giustizia include, per quanto sia praticabile, tra l'altro: "attribuire ad essa una quota appropriata delle risorse del giudice, tenendo conto della necessitá di riservare le risorse agli altri casi”. Così intenso, il princpio di proporzionalità può essere ambientato nell'esperienza processuale italiana come un aspetto del valore costituzionale della efficienza nella disciplina del processo, che si desume dall'affermazione della sua ragionevole durata (art. 111 , comma $2^{\circ}$, cost.)". 
público, ${ }^{29}$ atuando diretamente em prol da maior eficiência do sistema justiça. ${ }^{30}$ Interessante perspectiva da atuação da flexibilidade procedimental e da proporcionalidade, que surge em algumas reformas processuais, é a indicação, tanto no início como no curso do procedimento judicial, de encaminhamento da causa para os mecanismos consensuais de solução de conflitos, por exemplo, conciliação/mediação, ${ }^{31}$ e que se mostram importantes para evitar o dispêndio de recursos judiciais quando possível buscar outras formas de solução do litígio, permitindo, com isso, a utilização destes chamados meios alternativos de solução de conflito como mais uma ferramenta de gestão processual. ${ }^{32}$

A flexibilidade procedimental e a proporcionalidade interagem para buscar o melhor procedimento e a forma mais adequada de aplicação dos recursos judiciais, de acordo com as peculiaridades de cada causa concretamente considerada, e por isso ambos caminham no sentido de incrementar a gestão ou direção processual pelo juiz. ${ }^{33}$

Todavia, tal incremento nos poderes de gestão procedimental do juiz, advinda da conjugação da flexibilidade com a proporcionalidade, não se dá por meio da atuação unilateral ou imperativa do juiz, mas sim envolve estreita participação e interrelação das partes com o juiz, de modo a atuar o princípio de colaboração, para que as opções ou orientações procedimentais sejam debatidas e decidas em conjunto com as partes, ou seja, em diálogo entre partes, advogados e juiz. ${ }^{34}$

29 LUPOI, Michele Angelo. Tra flessibilità e semplificazione - Un embrione di case management all'italiana? Bologna: Bononia University Press, 2018, p. 59: "Nell'ambito di una nuova visione della giurisdizione, intesa come 'servizio pubblico' per l'attuazione dei diritti soggettivi dei privati, si ritiene che non si possa continuare a pensare alla singola causa come paradigma di riferimento del modello del giusto processo, senza considerare il panorama complessivo di riferimento: ovvero la molteplicità delle cause civili contemporaneamente pendenti in corti più o meno sovraccariche e prive di mezzi e personale".

30 LUPOI, Michele Angelo. Tra flessibilità e semplificazione - Un embrione di case management all'italiana? Bologna: Bononia University Press, 2018, p. 60.

31 LUPOI, Michele Angelo. Tra flessibilità e semplificazione - Un embrione di case management all'italiana? Bologna: Bononia University Press, 2018, p. 97.

32 LUPOI, Michele Angelo. Tra flessibilità e semplificazione - Un embrione di case management all'italiana? Bologna: Bononia University Press, 2018, p. 98: "La mia attenzione, infatti, intende concentrarsi su quegli istituti che possano essere utilizzati dal giudice, nel caso concreto, nell'ambito di una attività gestoria del processo, intesa in senso lato, nel prisma del principio di proporzionalità, che induce a concentrarsi sulle liti per le quali non si configuri altro esito se non la decisione appunto giudiziale".

33 LUPOI, Michele Angelo. Tra flessibilità e semplificazione - Un embrione di case management all'italiana? Bologna: Bononia University Press, 2018, p. 60.

34 LUPOI, Michele Angelo. Tra flessibilità e semplificazione - Un embrione di case management all'italiana? Bologna: Bononia University Press, 2018,p. 61: "nelle più recenti riforme processuali di molti Stati stranieri, il principio di proporzionalità, inteso come adattamento degli schemi processuali alle caratteristiche della fattispecie individuale, non è mai attuato sempliciemente attribuendo poteri impositivi al giudice in merito alla scansione delle tempistiche del processo. Piuttosto, esso è di norma inserito in un contesto in cui le scelte in merito all'iter della causa si basano sul dialogo tra i soggetti coinvolti nel processo, ovvero, giudice, parti e avvocati difensori. In quest'ottica, dunque, il principio di proporzionalità si allaccia inscindibilmente al 
A moderna leitura ou atuação dos princípios de flexibilidade procedimental e proporcionalidade exige a aplicação da colaboração, ou da participação das partes no debate dos melhores caminhos procedimentais, para, juntamente com o juiz, realizar as escolhas ou opções que permitam a melhor gestão do procedimento. ${ }^{35}$

Não é, pois, no atual estágio da evolução do processo civil, oportuno e adequado deixar a gestão processual confiada apenas ao juiz: tal gestão, para assegurar a melhor passagem possível da previsão abstrata das normas processuais para sua aplicação ao caso concreto, de acordo com suas peculiaridades, deve ser exercida em conjunto com as partes, permeada pela ideia de colaboração. ${ }^{36}$

\section{FLEXIBILIDADE, PROPORCIONALIDADE E COLABORAÇÃO NO CPC/2015: AMBIENTE PARA GESTÃO PROCESSUAL CO- LABORATIVA}

Delineada brevemente as tendências evolutivas atuais do processo civil no cenário comparado, cumpre apurar se o atual CPC/2015 atua, e em que medida, modelo procedimental flexível, permeado pela proporcionalidade, a ser exercitado sob a direção processual do juiz em colaboração com as partes.

A proporcionalidade, na linha da melhor atuação da duração razoável do processo, permitindo maior eficiência da atuação judicial para solução das crises de direito material, encontra-se destacada nas normas fundamentais do $\mathrm{CPC} / 2015$, especialmente no art. $4^{\circ}$, ao se dispor que "as partes têm o direito de obter em prazo razoável a solução integral do mérito, incluída a atividade satisfativa", e reforçada no art. $8^{\circ}$, ao prever que a atuação judicial deve observar "a proporcionalidade, a razoabilidade, a legalidade, a publicidade e a eficiência”.

Também a colaboração é incorporada nas normas fundamentais do CPC/2015, inclusive em expressa e explícita combinação com a eficiência da justiça, quando se prevê que "todos os sujeitos do processo devem cooperar

c.d. principio di collaborazione che del primo non è una conseguenza quanto il presupposto e la condizione di operatività".

35 LUPOI, Michele Angelo. Tra flessibilità e semplificazione - Un embrione di case management all'italiana? Bologna: Bononia University Press, 2018, p. 65.

36 LUPOI, Michele Angelo. Tra flessibilità e semplificazione - Un embrione di case management all'italiana? Bologna: Bononia University Press, 2018, pp. 630/631: "Come non appare possibile che il medesimo modello processuale operi in riferimento a ogni specie di controversia, così, per contro, non è opportuno che la gestione del processo sia interamente e unicamente affidata al potere discrezionale del singolo giudice. Tra le regole processuali generali e astratte e il potere del singolo giudice di dirigere il processo, esistono spazi che possono e devono essere colmati con il contributo di ciascun operatore del diritto, nella consapevolezza che la cattedrale della giustizia è un edificio comune, alla manutenzione del quale tutti possono e debbono collaborare". 
entre si para que se obtenha, em tempo razoável, decisão de mérito justa e efetiva”.

Em relação à flexibilidade procedimental, apesar de não ter sido acolhida expressamente no CPC/2015,37 é certo que o novo Código tem muito mais abertura ou permeabilidade à flexibilidade do que o CPC/1973, pois admitiu com maior detalhamento a gestão processual pelo juiz, como se extrai do art. 139, II, IV, V, VI e IX, e acolheu, expressamente, a possibilidade de alterações procedimentais no âmbito dos negócios processuais atípicos regulados de forma ampla no art. $190 .{ }^{38}$

A doutrina também aponta que, no âmbito do CPC/2015, normas como a do art. $327, \mathbb{S} 2^{\circ}$ (escolha, no caso de cumulação de pedidos, pelo procedimento comum, conjugado com as técnicas processuais diferenciadas para os procedimentos especiais) e do art. 1049, par. único (combinação do procedimento comum com previsões inseridas em leis especiais), evidenciam o acolhimento da flexibilidade procedimental no novo Código ${ }^{39}$ Assim, a doutrina brasileira mais atual dá ênfase, no CPC/2015, à necessidade de flexibilização procedimental, permeada pela colaboração, inclusive com o alinhamento do direito brasileiro às novas tendências comparadas do processo civil. ${ }^{40}$

37 Tal como ocorria no âmbito do CPC/1973, em que a doutrina extraia o acolhimento implícito da flexibilidade procedimental, como, v.g., GAJARDONI, Fernando da Fonseca. Flexibilização procedimental: um novo enfoque para o estudo do procedimento em matéria procedimental. São Paulo: Atlas, 2008, pp. 136/137: “Os princípios da adequação e da adaptabilidade, apesar de não gozarem de previsão legal específica, parecem estar implícitos no sistema processual civil brasileiro”. Não obstante, a doutrina também preconizava, à época, a necessidade do acolhimento explícito na legislação tanto a ideia da colaboração como a da adaptabilidade procedimental, como, v.g., OLIVEIRA, Carlos Alberto Álvaro de. Efetividade e processo de conhecimento. Revista de Processo, São Paulo, RT, vol. 96, out-dez/1999, pp. 59 - 69, que já destacava, no âmbito do CPC/1973, que, para maior efetividade do processo de conhecimento, seria necessário reformas de "cunho legislativo", dentre as quais indicava, por exemplo, as seguintes: "Antes de mais nada, impõe-se a adoção do princípio da cooperação, como pedra angular e exponencial do processo civil. (...) O estabelecimento, como princípio geral do processo, do princípio da adequação formal, facultando ao juiz, obtido o acordo das partes, e sempre que a tramitação processual prevista na lei não se adapte perfeitamente às exigências da demanda aforada, a possibilidade de amoldar o procedimento à especificidade da causa, por meio da prática de atos que melhor se prestem à apuração da verdade e acerto da decisão, prescindindo dos que se revelem inidôneos para o fim do processo".

38 DIDIER JR., Fredie; CABRAL, Antônio do Passo; CUNHA, Leonardo Carneiro da. Por uma nova teoria dos procedimentos especiais - dos procedimentos às técnicas. Salvador: Editora JusPodium, 2018, pp. 78/79: “E essa adaptação é possível no CPC-2015, pois o Código tem a tônica da flexibilização do procedimento e das formalidades dos atos processuais, seja uma flexibilização operada pelo juiz (case management), seja pelas partes (negócios jurídicos processuais)".

39 DIDIER JR., Fredie; CABRAL, Antônio do Passo; CUNHA, Leonardo Carneiro da. Por uma nova teoria dos procedimentos especiais - dos procedimentos às técnicas. Salvador: Editora JusPodium, 2018, pp. 80/81: “A mudança do modelo de procedimento comum rígido para um procedimento comum flexível também pode ser vista, com muita facilidade, nos comandos normativos dos arts. $327, \mathbb{S} 2^{\circ}$, e 1.049 , parágrafo único, já examinados, que permitem a inserção, no procedimento comum, de técnicas especiais de diferenciação procedimental".

40 DIDIER JR., Fredie; CABRAL, Antônio do Passo; CUNHA, Leonardo Carneiro da. Por uma nova teoria dos procedimentos especiais - dos procedimentos às técnicas. Salvador: Editora 
Além disso, a flexibilidade procedimental também pode ser extraída da conjugação, dentro do próprio processo, da técnica da solução judicial com outros meios de solução de conflitos, baseados na busca de consenso, como mediação/conciliação (art. $3^{\circ}, \mathbb{\$} 3^{\circ}$, art. 139 , V, arts. 165 a 175 do $\mathrm{CPC} / 2015$ ), em que se admite que o juiz, na condição de gestor do procedimento, possa paralisar o procedimento judicial para encaminhar a partes para centros de mediação/conciliação judiciais ou extrajudiciais, ${ }^{41}$ e que pode se inserir como importante ferramenta tanto de flexibilidade procedimental como de gestão processual. ${ }^{42}$

Pode-se, até, ensaiar, ainda que de forma incipiente, o vislumbre de determinados "circuitos" no CPC/2015 no âmbito do próprio procedimento comum (sem contar as possibilidades, já citadas, de conjugação do procedimento comum com as técnicas dos procedimentos especiais), e que também podem ser inseridos no contexto maior da flexibilidade procedimental, como, por exemplo:

a) circuito abreviado, com o uso, no procedimento comum do processo de cognição, dos diversos mecanismos do indeferimento da petição inicial e do julgamento liminar de improcedência do pedido (arts. 330 a 332); e também com o uso das tutelas provisórias (arts. 294/311), especialmente da tutela da

JusPodium, 2018, p. 81: "Na realidade, essa mudança de um modelo procedimental comum rígido para um procedimento comum flexível insere-se no contexto macro de tendências mundiais, que abrangem (a) desjudicialização dos conflitos; (b) racionalização dos processos; (c) reestruturação da organização judiciária. E é na racionalização do processo que se insere a necessidade de flexibilização procedimental, com simplificação dos atos, especialmente em sua forma. A partir da própria cooperação e da valorização do autorregramento da vontade no processo, é certo que se adotou uma concepção dinâmica do procedimento, com diversidade e flexibilidade".

41 Relembre-se com LUPOI, Michele Angelo. Tra flessibilità e semplificazione - Un embrione di case management all'italiana? Bologna: Bononia University Press, 2018, pp. 97/98: "Inoltre, in alcune recenti riforme processuali, tra le attività in cui si concretizza la gestione manageriale della lite si prevede anche il ricorso alle c.d. A.D.R., normalmente nella fase iniziale della lite ma che nel corso della stessa. L'esperienza comparatistica dimostra, in effetti, come la dimensione contemporanea del processo civile proponga uno stretto rapporto tra attività lato sensu conciliative e tradizionale ruolo aggiudicatorio del giudice. La soluzione in via transattiva della lite è sempre incoraggiata, anche attribuendo al giudice il ruolo di stimolare tale esito, sia direttamente che indirettamente. A questa visione del processo, il nostro ordinamento non è rimasto insensibile. Anzi, una delle linee evolutive più marcate delle recenti riforme processuale italiane è proprio quella tesa a 'marginalizzare' l'intervento decisorio del giudice, a favore di strumenti alternativi per la soluzione della lite".

42 CADIET, Loic. Perspectivas sobre o sistema da justiça francesa - seis lições brasileira. São Paulo: Revista dos Tribunais, 2017, p. 36: "Desde um ponto de vista externo, o pluralismo do sistema justiça deve conduzir à combinação de diferentes modalidades de resolução de controvérsias - as jurisdicionais e s amigáveis, as judiciais e as extrajudiciais, os polos de competência jurisdicional especializados e os escalões jurisdicionais de aproximação generalistas, oferecendo-se a cada tipo de conflito ou a cada conflito o tipo de resolução que lhe convém. É tarifa de a lei facilitar a passagem de um modo para a outro quando cada um deles apresentar garantias equivalentes de boa justiça. O desenvolvimento contemporâneo das modalidades alternativas de resolução de conflitos participa da promoção desse pluralismo do sistema de justiça - e pode, inclusive, ser concebido como um instrumento do 'management' judicial”. Cf. também THEODORO JÚNIOR, Humberto; ANDRADE, Érico. Impactos da Constituição Federal na evolução do processo civil. In: MORAES, Guilherme Peña de (Org.). 30 Anos da Constituição Federal e o Direito Brasileiro. Rio de Janeiro: Forense-Gen, 2018, pp. $351 / 352$. 
evidência (art. 311) e da nova potencialidade de tal decisão sumária resolver, por si só, a crise do direito material, sem necessidade do processo de cognição plena (art. 304, $\$ 1^{\circ}$ );

b) circuito médio, com o julgamento conforme o estado do processo, especialmente com o julgamento antecipado de mérito, integral ou parcial (arts. 354 a 356);

c) circuito longo, no âmbito do procedimento comum com a aplicação da fase probatória, mas em cenário que o juiz conta com importantes instrumentos de flexibilização/gestão processual, como o saneamento adequado do processo, inclusive pela via compartilhada (art. $357, \mathbb{S} 3^{\circ}$ ), e da gestão adequada da produção da prova, com possibilidade de alteração da ordem de sua produção, nos termos do art. 139, VI, ou mesmo com a inversão do ônus da prova, promovida judicial ou negocialmente (art. 373, $\mathbb{S} \mathbb{S} 1^{\circ}$ a $4^{\circ}$ ).

O CPC/2015 também acolhe e incrementa os poderes de gestão processual pelo juiz, especialmente no art. 139, ao arrolar os poderes do juiz para dirigir o processo, envolvendo aplicação de medidas coercitivas e indutivas (inciso IV); promoção, a qualquer tempo, da tentativa de autocomposição entre as partes (inciso V); dilatação de prazos processuais e, como dito, alteração da ordem de produção da prova, para melhor adequação do processo ao conflito (inciso VI); determinação judicial para suprimento de pressupostos processuais e vícios processuais (inciso IX), dentre outras medidas.

Certo, também, que se insere no cenário da gestão processual as perspectivas de cooperação internacional (arts. 26 a 41 do CPC/2015) e nacional (arts. 67 a 69 do CPC/2015) entre juízos, ${ }^{43}$ valendo ressaltar, no âmbito da cooperação nacional, a previsão de realização de atos processuais concertados entre juízes cooperantes (art. 69, IV, CPC/2015), dentre os quais, por exemplo, a apresentação de provas e coletas de documentos (art. 69, $\$ 2^{\circ}, \mathrm{II}, \mathrm{CPC} / 2015$ ) e a centralização de processos repetitivos (art. 69, $\$ 2^{\circ}$, VI, CPC/2015), que podem constituir importantes ferramentas para a gestão processual conjunta entre juízos diversos.

Trata-se, pois, no âmbito do gerenciamento ou gestão processual, da ampliação dos poderes do juiz na condução do processo, com atuação mais

43 Cf, THEOdORO JÚNIOR, Humberto. Curso de Direito Processual Civil. 56 a ed. Rio de Janeiro: Gen-Forense, 2015, vol. I, p. 263: "o novo Código, na implantação de uma política de informalidade e agilidade, destinada a incrementar a eficiência do serviço judiciário (...) instituiu o dever de recíproca cooperação aos órgãos do Poder Judiciário”. Registre-se que, antecedentemente à edição das normas do CPC/2015, para regular a cooperação judiciária nacional e internacional, o tema já havia sido objeto de tratamento na Resolução n ${ }^{\circ} 38$, de 3 de novembro de 2011, do Conselho Nacional de Justiça - CNJ, reconhecendo expressamente que a sistemática "cooperação judiciária constitui mecanismo contemporâneo, desburocratizado e ágil para o cumprimento de atos judiciais fora da esfera de competência do juízo requerente ou em intersecção com ele" e ainda se destacando que a cooperação judiciária fomenta "a participação dos magistrados de todas as instâncias na gestão judiciária". Disponível em http:// www.cnj.jus.br/atos-normativos?documento=285. Acesso em 25/03/2019. 
efetiva na busca da realização da maior eficiência da justiça. Tudo, reitere-se, para permitir e garantir a melhor adaptação do procedimento ao caso concreto, no interesse das partes e do próprio processo em realizar uma justiça mais célere e com menor custo, de acordo com as necessidades reais de cada caso. ${ }^{44} \mathrm{E}$, claro, o incremento de tais poderes de gestão processual do juiz impõe, na linha evolutiva mais atual do processo civil, seu exercício de forma colaborativa com as partes, e não unilateralmente, como muito bem ressalta a doutrina italiana. ${ }^{45}$

Entretanto, registre-se, o aumento dos poderes do juiz na gestão processual não importa, por si só, aumento dos poderes instrutórios do juiz, já que as duas perspectivas são diversas e uma pode caminhar separada da outra: na gestão processual é necessário reforçar e aumentar os poderes do juiz na condução e gerenciamento processual, sem necessariamente ampliar os poderes do juiz para determinar, de ofício, a produção de prova. ${ }^{46}$

Deve-se, pois, levar em conta a nítida diferença entre as duas situações: num caso, diante do ambiente gerencial do processo, aumentam-se os poderes de direção formal do juiz; e em outro, tem-se panorama diverso, atinente à ampliação dos poderes do juiz para determinar, de ofício, provas. A distinção deve ser destacada porque, como aponta a doutrina italiana, é muito comum a confusão entre as duas distintas situações sob o nome de ativismo judicial. ${ }^{47}$

44 DE CRISTOFARO, Marco. Case management e riforma del processo civile, tra effettività della giurisdizione e diritto costituzionale al giusto processo. Rivista di Diritto Processuale, Padova: Cedam, anno LXV, 2010, n. 2, p. 283: “(...) il case management si configura primariamente quale mezzo di adattamento della disciplina procedimentale alle peculiarità del caso concreto, sì da non comprimere le esigenze di difesa e di approfondimento delle parti e al contempo però consentendo a ciascun contenzioso il 'giusto' grado di attenzione da parte del servizio di giustizia (non troppo poco, ma neppure troppo)".

45 Cabe relembrar, aqui, as importantes considerações de LUPOI, Michele Angelo. Tra flessibilità e semplificazione - Un embrione di case management all'italiana? Bologna: Bononia University Press, 2018, p. 61, a respeito do aumento dos poderes de gestão processual do juiz estar diretamente ligado ao princípio de colaboração: "nelle più recenti riforme processuali di molti Stati stranieri, il principio di proporzionalità, inteso come adattamento degli schemi processuali alle caratteristiche della fattispecie individuale, non è mai attuato sempliciemente attribuendo poteri impositivi al giudice in merito alla scansione delle tempistiche del processo. Piuttosto, esso è di norma inserito in un contesto in cui le scelte in merito all'iter della causa si basano sul dialogo tra i soggetti coinvolti nel processo, ovvero, giudice, parti e avvocati difensori. In quest'ottica, dunque, il principio di proporzionalità si allaccia inscindibilmente al c.d. principio di collaborazione che del primo non è una conseguenza quanto il presupposto e la condizione di operatività".

46 Como aponta DE CRISTOFARO, Marco. Case management e riforma del processo civile, tra effettività della giurisdizione e diritto costituzionale al giusto processo. Rivista di Diritto Processuale, Padova: Cedam, anno LXV, 2010, n. 2, p. 283, o case management permanece "straneo alle tematiche dei poteri/doveri del giudice quanto all'approfondimento officioso di questioni insorte nel corso del processo o alla tematica dei poteri istruttori o addirittura all'onere di segnalazione alle parti della necessità di integrare/modificare le proprie allegazioni”.

47 Nesse sentido, confira-se a precisa anotação de CAVALLONE, Bruno. In difesa della veriphobia. Rivista di Diritto Processuale, Padova: Cedam, anno LXV, 2010, n. 1, p. 17 : "L'altro, di carattere invece teorico, è che nel dibattito si sono largamente confuse, hinc ed inde, le questioni che riguardano i poteri di iniziativa probatoria del giudice (materielle Prozessleitung nella terminologia della vecchia dottrina tedesca) con quelle che attengono ai suoi poteri di direzione formale del procedimento (formelle Prozessleitung), che hanno ben 
Assim, o aumento dos poderes de direção e gerenciamento processual do juiz tem por objetivo a economia e a melhoria da gestão do processo, inclusive permeada pela colaboração das partes, a indicar que tal cenário de atuação envolve necessariamente a atuação conjunta do juiz com as partes, e não guarda relação com eventual ampliação dos poderes instrutórios do juiz, que se baseia em concepção diversa, aquela dos esclarecimentos dos fatos para delineamento da verdade real, com participação ativa do juiz na instrução processual.

Nesse ponto, inclusive, se preconiza no direito brasileiro, o uso do termo gestão ou gerenciamento processual até para se afastar do cenário conhecido como “ativismo judicial”, ${ }^{48}$ expressão quase sempre vem utilizada com conotação negativa, de atuação do juiz atropelando a atuação das partes e muitas vezes até invadindo a esfera de outras funções estatais, ou seja, extrapolando os limites constitucionais da sua atuação. ${ }^{49}$

diversa natura e ben maggiore peso nell'economia del processo. È a causa di questa confusione, mi sembra, che molti studiosi continuano a valutare l' 'attivismo' e la 'passività' dei giudici di vari Paesi con il metro dei poteri a loro inutilmente concessi dai rispettivi legislatori in materia di prove, anziché verificare quale sia l'estensione dei loro poteri di case management: ciò che forse condurrebbe a considerare anche troppo attivi, e magari persino 'autoritari', propri gli 'inerti' giudici inglesi e americani, come possono constatare gli avvocati continentali quando occasionalmente si trovano ad avere a che fare con loro".

48 A doutrina, por exemplo, LOPES, Maria Elizabeth de Castro. Ativismo judicial e novo Código de Processo Civil. Revista de Processo, São Paulo, RT, vol. 205, mar/2012, pp. 301-306, destaca que "a expressão ativismo judicial vem sendo utilizada de maneira frequente nos meios acadêmicos e na jurisprudência, mas seu conceito ainda não foi fixado em caráter definitivo”, mas reconhece que "de modo geral, fala-se em ativismo ou para indicar a ingerência do Judiciário em temas políticos (por exemplo, a quem pertence o mandato parlamentar?) ou para caracterizar a atividade do juiz no processo, dando ênfase à liberdade e aos poderes de atuação do magistrado (por exemplo, para permitir que o juiz determine provas de ofício)". Também MOTTA, Francisco José Borges; TASSINARI, Clarissa. Ativismo judicial e decisões por princípio: uma proposta de fixação dos limites da atuação do Poder Judiciário. Revista de Processo, São Paulo, RT, vol. 283, set/2018, pp. 481-499, reconhecem que "há uma grande dificuldade de se definir o ativismo judicial”, mas indicam que normalmente a expressão vem associada à judicialização da política: "Essas premissas teóricas, que realçam a centralidade do elemento jurisdicional do Estado, bem como o elemento político do Direito, provocam uma radical modificação na forma como era concebido o exercício da jurisdição constitucional no Brasil. A partir disso, é possível afirmar que duas expressões passaram a estar diretamente vinculadas à atividade jurisdicional: ativismo judicial e judicialização da política".

49 De fato, a expressão "ativismo judicial” normalmente é ligada à extrapolação dos limites constitucionais da atuação judicial, como apontam ABBOUD, Georges; LUNELLI, Guilherme. Ativismo judicial e instrumentalidade do processo - diálogos entre discricionariedade e democracia. Revista de Processo, São Paulo, RT, vol. 242, abr/2015, pp. 21 - 47: "Não por outra razão, a compreensão do ativismo judicial sempre nos remete a discussões sobre a normal e adequada função/atuação dos juízes. Quando falamos em ativismo, obrigatoriamente, falamos em extrapolação de limites na atividade judicante". E por isso mesmo, como ressaltam os mesmos autores, não se limita ativismo à atuação das cortes superiores: "Essa é a razão pela qual o ativismo não se encontra limitado à atuação das Cortes Superiores ou à interpretação do texto constitucional. Sempre que uma decisão, proferida por qualquer juiz ou instância, encontrar fundamento nas convicções pessoais do julgador, restando ignorado ou deturpado o sentido de um texto democraticamente posto, estaremos diante de posturas ativistas". Também MOTTA, Francisco José Borges; TASSINARI, Clarissa. Ativismo judicial e decisões por princípio: uma proposta de fixação dos limites da atuação do Poder Judiciário. Revista de Processo, São Paulo, RT, vol. 283, set/2018, pp. 481-499, destacam que “ativismo e supremacia judicial, dado o recorte conceitual proposto neste pequeno ensaio, são elementos nocivos para 
Portanto, para evitar confusões desnecessárias, talvez seja recomendável a utilização da expressão gerenciamento ou gestão processual até mesmo para destacar que em tal contexto não se ampliam os poderes do juiz para atuar o direito fora da legalidade ou dos marcos constitucionais, e nem se ampliam os poderes instrutórios do juiz para busca da verdade real. Assim, não se atua aqui o cenário descrito no âmbito do assim chamado "ativismo judicial", mas apenas se situa o juiz como gestor do processo, para definir, em conjunto com as partes, com a participação das partes, as melhores opções procedimentais em atenção ao caso concreto, permeando tal gestão processual pela flexibilização, colaboração e proporcionalidade no uso dos recursos judiciais.

Em suma, a flexibilidade é forma de gestão do processo, gestão a ser coordenada pelo juiz (art. 139, CPC/2015) que, em colaboração com as partes (art. $\left.6^{\circ}, \mathrm{CPC} / 2015\right)$, deve atuar para solução do direito material, de acordo com a complexidade e caraterísticas do caso concreto, gerindo melhor a aplicação dos recursos processuais, na busca da maior eficiência do processo e da justiça para atuar o direito material (arts. $4^{\circ}$ e $\left.8^{\circ}, \mathrm{CPC} / 2015\right):{ }^{50}$ conjugação da flexibilidade procedimental, com gestão processual adequada, tudo permeado pela colaboração, em prol da melhor aplicação dos recursos judiciais, na busca de eficiência da atuação jurisdicional.

A seguir, passa-se ao tratamento das perspectivas colaborativas entre partes e juiz, inclusive no âmbito dos negócios processuais, como um dos instrumentos disponíveis para operar a melhor gestão processual flexível, permitindo o uso ou alocação mais adequada dos recursos judiciais. ${ }^{51}$

o caráter democrático da comunidade política, na medida em que implicam extrapolação de limites constitucionais".

50 BIAVATI, Paolo. Flessibilità, semplifcazione e gestione del processo civile: la prospettiva italiana. In: ZUFELATO, Camilo; BONATO, Giovanni; SICA; Heitor Vitor Mendonça; CINTRA, Lia Carolina Batista (Coord). I Colóquio Brasil-Itália de Direito Processual Civil, Salvador, Editora Jus Podium, 2016, p. 208: "In primo luogo, la nozione di flessibilità ovvero di elasticità. (...) Mi sembra che la si possa definire come un modo di essere delle norme, che le rende il più possibile adattabili al caso concreto e che permette quindi il maggiore avvicinamento possibile della norma astratta alle esigenze del singolo processo, del processo reale. L'elasticità non è discrezionalità, né mero capriccio che piega la regola alla situazione; non è patrimonio del solo giudice ma strumento comune e condiviso con le parte. La disposizione flessibile è quella che configura diversi possibili sbocchi di una data fase del processo, tutti prevedibili, ma uno solo dei quali sarà scelto nel singolo caso".

51 CUEVA, Ricardo Villas Bôas. Flexibilização do procedimento e calendário processual no novo CPC in CABRAL, Antonio do Passo; NOGUEIRA, Pedro Henrique (Coord). Negócios Processuais. $3^{\text {a }}$ ed. Salvador: Editora Jus Podium, 2017, p. 532/533. 


\section{AS NOVAS PERSPECTIVAS DA GESTÃO PROCESSUAL NO $\mathrm{CPC} / 2015$}

O cenário da colaboração entre partes e juiz, apresentado como norma fundamental no art. $6^{\circ}$ do CPC/2015, é o pano de fundo ${ }^{52}$ para acolhimento de norma geral que admite os negócios processuais atípicos (art. 190, CPC/2015) ${ }^{53}$ e também para o delineamento, em vários outros dispositivos do Código, de cenários colaborativos, em sentido amplo, entre partes e juiz, como mecanismo de gestão processual, ${ }^{54}$ tais como: calendário processual (art. 191); saneamento compartilhado $\left(\operatorname{art} .357, \mathbb{S} \mathbb{S} 2^{\circ}\right.$ e $3^{\circ}$ ); ajuste para indicação do perito pelas partes (art. 471); escolha de comum acordo mediador/conciliador (art. 168); redução de prazos $\left(\operatorname{art.} 222, \mathbb{S} 1^{\circ}\right)$; distribuição ônus da prova $\left(\operatorname{art.} 373, \mathbb{S} \mathbb{S} 3^{\circ}\right.$ e $4^{\circ}$ ); escolha da modalidade de liquidação (art. 509, I).

O chamado "calendário do processo", por exemplo, pode ser utilizado como interessante e eficiente ferramenta de gestão processual ${ }^{55}$ - e até mesmo para atuar a flexibilização procedimental ${ }^{56}$-, que representa, ao mesmo tempo, importante mecanismo para atuação da colaboração entre partes e juiz, ${ }^{57}$

52 CADIET, Les nouvelles tendances de la procédure civile en France in Novos Rumos da Justiça Cível: Conferência Internacional, Lisboa, abril 2008. Coimbra: Cejur-Coimbra Editora, 2009, p. 38: "La contractualisation du procés est dans la logique du principe de coopération du juge et des parties (...)".

53 Não se irá, neste trabalho, apresentar maiores aprofundamentos em torno da figura dos negócios processuais, especialmente porque o autor já tratou do tema em outro trabalho, ao qual se remete o leitor interessado em analisar a temática dos negócios processuais em si, suas possibilidades e limites: ANDRADE, Érico. A "contratualização" do processo. In: THEODORO JÚNIOR, Humberto (coord.). Processo Civil Brasileiro - novos rumos a partir do CPC/2015. Belo Horizonte: DelRey Editora, 2016, pp. 47-65.

54 Nesse sentido, CADIET, Loic. Perspectivas sobre o sistema da justiça civil francesa. São Paulo: Revista dos Tribunais, 2017, p. 89: “a convenção entre as partes não é apenas um instrumento de solução do litígio, mas também se converteu em técnica de gestão do processo judicial”.

55 LUPOI, Michele Angelo. Tra flessibilità e semplificazione - Un embrione di case management all’italiana? Bologna: Bononia University Press, 2018, p. 77, leciona que o calendário processual pode ser visto como "uno strumento di organizzazione e gestione del processo civile in modo più efficiente".

56 CUEVA, Ricardo Villas Bôas. Flexibilização do procedimento e calendário processual no novo CPC. In: CABRAL, Antonio do Passo; NOGUEIRA, Pedro Henrique (Coord). Negócios Processuais. $3^{\text {a }}$ ed. Salvador: Editora Jus Podium, 2017, p. 527: "Uma das mais instigantes inovações do Código de Processo Civil de 2015 consiste na possibilidade de flexibilizar o procedimento por ato do juiz para adequá-lo às necessidades do conflito (art. 139, VI, do NCPC), por meio de convenção entre as partes (art. 190, NCPC) ou, ainda, pela fixação, de comum acordo entre juiz e as parts, de calendário processual (art. 191, NCPC). Trata-se de novo paradigma voltado a um modelo de gerenciamento de processos que rompe o monopólio do juiz na condução do processo e enseja a gestão compartilhada do procedimento". COSTA, Eduardo José da Fonseca. Calendarização processual. In: CABRAL, Antonio do Passo; NOGUEIRA, Pedro Henrique (Coord). Negócios Processuais. $3^{\mathrm{a}}$ ed. Salvador: Editora Jus Podium, 2017, p. 518, também destaca que o calendário pode ser montando com ou sem flexibilização procedimental: "Por conseguinte, pode haver (a) calendário com flexibilização procedimental e (b) calendário sem flexibilização procedimental”.

57 LUPOI, Michele Angelo. Tra flessibilità e semplificazione - Un embrione di case management all'italiana? Bologna: Bononia University Press, 2018, p. 87: "D'altro canto, il calendario istruttorio, nell'attuale assetto ordinamentale, rappresenta una delle poche occasioni di 
quando juiz e os advogados das partes, em atenção às características do caso concreto, ajustam as datas para prática dos atos processuais de instrução e de troca de peças de defesa, bem como da própria decisão. ${ }^{58}$

Essa técnica do direito francês ${ }^{59}$ foi encampada pelo direito italiano na reforma de 2009, produzida pela lei n. 69 que, entre várias outras modificações, introduziu o calendário do processo, ${ }^{60}$ por meio do qual são ajustadas previamente, no início da causa, as datas para a prática dos atos processuais, inclusive instrutórios, até a decisão. ${ }^{61}$ Este mesmo caminho inovativo foi trilhado pelo direito brasileiro com o CPC/2015 que também acolheu figura do calendário do processo no seu art. 191.

O calendário é fixado em cada processo de acordo com as peculiaridades da causa concretamente considerada: não se trata de mera atividade arbitrária do juiz, pois é realizada não só em consonância com a natureza da lide, com urgência na solução da controvérsia, com a sua complexidade, mas também

valorizzare, nel processo ordinario, il principio di collaborazione tra giudice e parti in un'ottica contemporanea, nel senso di rapporto dinamico di contributo reciproco nell'organizzazione concordata dello svolgimento dell'iter processuale".

58 CANELLA, Maria Giulia. Gli accordi processuali francesi volti alla "regolamentazione collettiva" del processo civile. Rivista Trimestrale di Diritto e Procedura Civile, Milano, Giuffrè, anno LXIV, 2010, n. 2, p. 557: "Il calendario prevede il numero delle difese ed i rispettivi termini, la data della chiusura della fase istruttoria, quella in cui se terrà la discussione della causa, nonché quella della pronuncia della sentenza (artt. 763 e 764 c.p.c.)”. Cf. também CABRAL, Trícia Navarro Xavier. Reflexo das convenções em matéria processual nos atos judiciais. In: CABRAL, Antonio do Passo; NOGUEIRA, Pedro Henrique (Coord). Negócios Processuais. $3^{\mathrm{a}}$ ed. Salvador: Editora Jus Podium, 2017, p.353: “Assim, no calendário processual previsto no artigo 191 e parágrafos do CPC/2015, os sujeitos processuais adequam o ritmo e a duração da demanda às especificidades do caso concreto, atuando em cooperação para o alcance de uma decisão justa e efetiva em tempo razoável, em atendimento ao que preceitua o artigo $6^{\circ}$, do mesmo diploma legal".

59 CADIET, Loic. Perspectivas sobre o sistema da justiça civil francesa. São Paulo: Revista dos Tribunais, 2017, p. 98, leciona que o calendário processual na França nasceu da prática judicial e depois foi acolhido pela legislação: "Nascido da prática judiciária, esse tipo de convenção foi consagrado diante do Tribunal de Grande Instance pelo Decreto de 28 de dezembro de 2005.Nos termos do artigo 764, alínea 3, do CPC, o juiz responsável pela fase de instrução 'pode fixar os prazos necessários para a instrução da matéria (parágrafo 1), em função da sua natureza, urgência e complexidade, desde que obtido o consenso dos advogados. Esse calendário conterá o número de sessões previstas e tratará de datas, como a data e finalização, a data das sessões e, derrogando o primeiro e o segundo parágrafo do art. 450, a data da decisão (parágrafo 2). Os prazos fixados poderão ser prorrogados, mas apenas por causa grave e devidamente justificada (parágrafo 3). A decisão do juiz está subordinada ao acordo das partes - e ambos devem submeter-se ao acordo".

60 PICOZZA, Elisa. Il calendario del processo. Rivista di Diritto Processuale, Padova: Cedam, anno LXIV, 2009, n. 6, p. 1650. A norma de 2009 foi, depois, em 2011, revista para tornar o calendário mais efetivo, inclusivo tornando-o obrigatório, como destaca LUPOI, Michele Angelo. Tra flessibilità e semplificazione - Un embrione di case management all'italiana? Bologna: Bononia University Press, 2018, p. 78: "Per rendere tale dispozione più incisiva, pertanto, a distanza di un paio di anni, il legislatore l'ha profondamente riformulata, tramite l'art. 1-ter del decreto legge 13 agosto 2011, n. 138, convertito, con modificazioni, nella legge 14 settembre 2011, n. 148 (...) La norma, dunque, oggi prevede, in primo luogo, che la predispozione del calendario sia obbligatoria, come se desume dall'utilizzo del verbo 'fissa'".

61 PICOZZA, Elisa. Il calendario del processo. Rivista di Diritto Processuale, Padova: Cedam, anno LXIV, 2009, n. 6, p. 1655. 
com a participação direta das partes, em nítido regime colaborativo entre juízo e partes. O calendário, tanto no direito francês como no direito italiano, e no próprio direito brasileiro, não é fixado unilateralmente pelo juiz, mas com a participação colaborativa das partes, permitindo a instalação de clima de maior cooperação entre partes e juízo, além de se introduzir a prática negocial ou os acordos procedimentais. ${ }^{62}$

Assim, por exemplo, no âmbito da audiência inaugural prevista no art. 334 do CPC/2015, dedicada à tentativa inicial de conciliação ou mediação, acaso frustrada tal possibilidade, o juiz pode aproveitar a presença das partes e seus advogados ( $\mathbb{S} 9^{\circ}$ do art. 334), para ajustar o calendário do processo, em ambiente colaborativo (arts. $6^{\circ}$ e 191 ), ${ }^{63}$ no qual se poderia até mesmo partir para outros ajustes, como redução de determinados prazos processuais (art. 222, $\left.\mathbb{S} 1^{\circ}\right)$, ajuste para que as petições contenham limitações de número de páginas e anunciem claramente as razões de fato e de direito, em linha com atual tendência de simplificação processual, ${ }^{64}$ comunicação entre juízo e advogados

62 CADIET, Les nouvelles tendances de la procédure civile en France. n: BRITO, Rita. (Coord.). Novos Rumos da Justiça Cível: Conferência Internacional, Lisboa, abril 2008. Coimbra: Cejur-Coimbra Editora, 2009, p. 38: “(...) la consécration du contrat de procédure, avec le calendrier de mise en état, devant le tribunal de grande instance et la cour d'appel, ce calendrier, fixé avec l'accord des avocats, comportant "le nombre prévisible et la date des échanges de conclusions, la date de clôture, celle des débats et (...) celle du prononcé de la décision”. Cf. ainda CADIET, Loïc; JEULAND, Emmanuel. Droit judiciaire privé. 5 ed. Paris: LexisNexis, 2006. p. 567. No direito brasileiro conferir, por exemplo, NOGUEIRA, Pedro Henrique. Negócios Jurídicos Processuais. $3^{\mathrm{a}}$ ed. Salvador: Editora Jus Podium, 2018, p. 296. Não obstante, no direito brasileiro, COSTA, Eduardo José da Fonseca. Calendarização processual. In: CABRAL, Antonio do Passo; NOGUEIRA, Pedro Henrique (Coord). Negócios Processuais. $3^{\text {a }}$ ed. Salvador: Editora Jus Podium, 2017, p. 521, defende a imposição unilateral, pelo juiz, do calendário. Todavia, nesta hipótese, acredita-se que não se pode falar em calendário processual propriamente dito, que vai exigir sempre a atuação colaborativa das partes e juiz, mas simples ordenação processual unilateral, promovida pelo juiz com base no art. 139 do CPC/2015.

63 NOGUEIRA, Pedro Henrique. Sobre os acordos de procedimento no processo civil brasileiro. In: CABRAL, Antonio do Passo; NOGUEIRA, Pedro Henrique (Coord). Negócios Processuais. $3^{\mathrm{a}}$ ed. Salvador: Editora Jus Podium, 2017, p.104: “A previsão da audiência de conciliação no procedimento comum (CPC/2015, art. 334) pode favorecer à celebração desse tipo de convenção. As partes aqui ajustam como será o desenrolar do processo já em curso. O juiz, os conciliadores, inclusive em audiência, podem dialogar com as partes e sugerir a celebração de acordos de procedimento com vistas a obter um melhor rendimento do processo ou até acelerar sua tramitação". O em mesmo NOGUEIRA, Pedro Henrique. Negócios Jurídicos Processuais. $3^{\mathrm{a}}$ ed. Salvador: Editora Jus Podium, 2018, p. 295, em outra obra, reitera que "o momento propício para fixação do calendário é o da audiência da conciliação, no início do procedimento, ocasião em que os sujeitos preveem o átimo dos atos sucessivos do processo, dispensando as intimações posteriores, porquanto as datas serão definidas previamente, proporcionando maior rendimento e concretizando a eficiência (CPC/2015, art. $8^{\circ}$ )". Cf. também CABRAL, Trícia Navarro Xavier. Reflexo das convenções em matéria processual nos atos judiciais. In: CABRAL, Antonio do Passo; NOGUEIRA, Pedro Henrique (Coord). Negócios Processuais. $3^{\mathrm{a}}$ ed. Salvador: Editora Jus Podium, 2017, p. 355; e COSTA, Eduardo José da Fonseca. Calendarização processual. In: CABRAL, Antonio do Passo; NOGUEIRA, Pedro Henrique (Coord). Negócios Processuais. $3^{\text {a }}$ ed. Salvador: Editora Jus Podium, 2017, p. 515.

64 Nesse sentido, por exemplo, FINOCCHIARO, Giusepe. Il principio di sinteticità nel processo civile. Rivista di Diritto Processuale. Padova: Cedam, anno LXVIII, 2013, ns. 4-5, p. 865, ressalta que o processo civil italiano tem acolhido o princípio de "sinteticidade": "Le due circostanze appena riferite non consentono di dubitare non soltanto della piena applicabilità, 
por via eletrônica, com definição dos endereços e a forma de contagem de prazos a partir da intimação eletrônica.

E mais: se poderia também, neste momento inicial da audiência prevista no art. 334 do CPC/2015), realizar debate entre juiz e partes a respeito da possibilidade de adoção de um dos determinados "circuitos" identificados no CPC/2015 (curto, médio ou longo), a partir da complexidade da causa concretamente considerada, e inserção da opção eventualmente realizada de comum acordo entre juiz e partes no próprio calendário do processo. Aliás, a doutrina ressalta que a flexibilidade procedimento, com possibilidade de opção por determinados "circuitos procedimentais" mais adequados à causa, oferece grande campo para o desenvolvimento das convenções processuais. ${ }^{65}$

Não resta dúvidas, entretanto, de que, para funcionar como bom instrumento de gestão processual colaborativo, o calendário do processo vai exigir maior engajamento do juiz e das partes, principalmente na análise mais acurada do conteúdo do processo e do seu objeto logo no início da sua tramitação. ${ }^{66}$

ma anche della effettiva applicazione, nel c.d. 'diritto vivente', del pricipio di sinteticità anche nell'ambito del processo civil”. Cf. também BIAVATI, Paolo. Il linguaggio degli atti giudiziari. Rivista Trimestrale di Diritto e Procedura Civile. Milano, Giuffrè Editore, v. LXXI, 2017, n. 2, p. 470: "Probabilmente, si può ritenere che nel processo civile già esista una disposizione generale sulla sinteticità. Infatti, la l. n. 132 del 2015, modificando l'art. 16-bis della l. 221 del 2013, ha previsto che gli atti di parti e i provvedimenti del giudice depositati con modalità telematiche devono essere redatti in maniera sintetica" e conclui o mesmo autor, ob. cit., p. 483: "A mio avviso, deve progressivamente prendere vita un nuovo stile nella redazione degli atti giudiziari, del giudice e di parte. (...) Il primo è quello della sobrietà o, in altre parole, della ragionevole proporzione fra la lunghezza dell'atto e la complessità della causa, con un occhio di riguardo alla brevità". Aliás, este campo da sinteticidade dos atos processuais, como destaca CAPPONI, Bruno. Sulla "ragionevole brevità" degli atti processuali civili. Rivista Trimestrale di Diritto e Procedura Civile. Milano, Giuffrè Editore, v. LXVIII, 2014, n. 3, p. 1091, tem ampla possibilidade de aplicação a partir da atuação consensual das partes e do juiz, abrindose como interessante campo para a colaboração: "La verità è che ocorre sforzarsi di alimentare una cultura in cui le regole non scritte, o esortazioni non sanzionate (perché ben difficilmente sanzionabili), dovranno fondarsi soprattutto sul consenso, sulla dignità della professione, sull'utilità concreta del proprio contributo nel processo". Para crítica, na própria doutrina italiana, a tal princípio de "sinteticidade", conferir, por exemplo, TARUFFO, Michele. Note sintetiche sulla sinteticità. Rivista Trimestrale di Diritto e Procedura Civile, Milano, Giuffrè Editore, v. LXXI, 2017, n. 2, p. 453 e segs. obre o movimento mais amplo da simplificação do direito, cf. ANDRADE, Érico. A simplificação administrativa. In: BATISTA JÚNIOR, Onofre Alves; CASTRO, Sérgio Pessoa de Paula (Coord.). Tendências e Perspectivas do Direito Administrativo: uma visão da escola mineira. Belo Horizonte, Ed. Fórum, 2012, pp. 31-58.

65 LUPOI, Michele Angelo. Tra flessibilità e semplificazione - Un embrione di case management all'italiana? Bologna: Bononia University Press, 2018, p. 630: "In ultima analisi, in tutti i siste$\mathrm{mi}$ in cui si sono introdotti 'circuits' o 'tracks' procedurali, alla decisione in merito alle attività da intraprendere nel caso specifico si arriva dopo un confronto tra le parti e tra le parti e il giudice, in un'ottica improntata alla collaborazione 'istituzionale' che coinvolge i difensori delle parti in un ruolo che va altre la difesa del cliente. La decisione sul binario istruttorio, in effetti, offre l'occasione per valorizzare gli aspetti negoziali del processo ed elevare la collaborazione a parametro per canalizzare la discrezione del giudice".

66 LUPOI, Michele Angelo. Tra flessibilità e semplificazione - Un embrione di case management all'italiana? Bologna: Bononia University Press, 2018, p. 622, alerta que para o melhor funcionamento destes novos instrumentos, como a definição do circuito processual adequado, ou mesmo do calendário processual, exige-se avaliação prévia mais aprofundada da causa: "Il 
Outro interessante mecanismo, no CPC/2015, que merece destaque, como importante ferramenta de gestão processual que pode ser permeada pela colaboração, é o chamado saneamento "compartilhado" ou "cooperativo", 67 previsto no art. $357, \mathbb{S} \mathbb{S} 2^{\circ}$ e $3^{\circ}$, em que, nas causas complexas, o juiz deve "designar audiência para que o saneamento seja feito em cooperação com as partes" $\left(\mathbb{S} 3^{\circ}\right),^{68}$ momento em que se admite, inclusive, que as partes ajustem

problema fondamentale, per quanto riguarda il giudice, è che la decisione relativa all'istruttoria somaria presuppone uma valutazione sulla complessità della causa che, a sua volta, richiede un attento studio preventivo del fascicolo di causa prima dell'udienza".

67 GOMES, Gustavo Gonçalves. O saneamento cooperativo como roteiro de organização e julgamento do processo. 2016. 326 p. Tese (doutorado em direito). Pontifícia Universidade Católica de São Paulo - PUC-SP, São Paulo/SP, p. 15, já indicava a utilização da expressão "saneamento compartilhado" por Paulo Hoffman na obra "Saneamento Compartilhado", São Paulo: Quartier Latin, 2011, e sugere, com o CPC/2015, diante do maior relevo dado ao princípio da colaboração, o uso da expressão "saneamento cooperativo". Disponível em: https://tede2.pucsp. br/bitstream/handle/19546/2/Gustavo\%20Goncalves\%20Gomes.pdf. Acesso em 04/04/2019. Cabe lembrar que, 2004, WAMBIER, Luiz Rodrigues, A audiência preliminar como fator de otimização do processo. O saneamento "compartilhado" e a probabilidade de redução da atividade recursal das partes. Revista de Processo, São Paulo, RT, vol. 118, nov/dez 2004, pp. 137-142, já sustentava a necessidade do saneamento compartilhado no âmbito da audiência preliminar prevista no art. 331 do CPC/1973: "Poucos se deram conta do fato de a audiência preliminar ter sido trazida para o direito brasileiro como a oportunidade, desde que frustrada a tentativa de conciliação, de se realizar aquilo que nos permitimos chamar de 'saneamento compartilhado"”. E a seguir acrescenta o mesmo autor: "A audiência preliminar é, a nosso ver, um momento extraordinariamente relevante para que se dê um contacto mais direto do magistrado com as partes e/ou seus procuradores, justamente naquela 'delicada fase do saneamento, em que, com a verificação da ausência de vícios processuais relevantes, ou com sua correção, se definem os limites dentro dos quais deve permanecer a discussão no processo, mediante a fixação dos pontos sobre os quais incidirá a atividade probatória'”. Também HOFFMAN, Paulo. Saneamento Compartilhado. São Paulo: Quartier Latin, 2011, p. 94/95, sustentava a possibilidade de saneamento compartilhado no CPC/1973, apontando o art. 331, $\$ 2^{\circ}$, como base legal para tanto: "No presente trabalho adotamos a expressão 'saneamento compartilhado' por entendermos ser a que mais apropriadamente representa a ideia de que a decisão de saneamento do processo não seja mais proferida pelo juiz isoladamente, sem a participação das partes, mas, sim, sempre em conjunto com elas e de forma mais 'negociada' possível. A base legal da existência do saneamento compartilhado está expressa no $\$ 2^{\circ}$ do art. 331 do CPC e não depende, portanto, de qualquer reforma legislativa, mas apenas de sua efetiva realização na prática, criando-se o hábito pela praxe forense". Não obstante, parte da doutrina considera que o saneamento compartilhado é inovação do CPC/2015, como, v.g., LIMA, Marcellus Polastri; DIAS, Luciano Souto, Reflexões e proposições sobre a audiência de saneamento compartilhado no Código de Processo Civil de 2015. Revista de Processo, São Paulo, RT, vol. 268, jun/2017, pp. 71-97: "Uma das principais inovações do CPC/2015 corresponde à previsão quanto à possibilidade de o saneamento do processo ocorrer de forma compartilhada, em cooperação entre as partes e o juiz, devendo ser designada uma audiência para tal finalidade sempre que a causa apresentar complexidade nas matérias de fato ou de direito".

68 LIMA, Marcellus Polastri; DIAS, Luciano Souto, Reflexões e proposições sobre a audiência de saneamento compartilhado no Código de Processo Civil de 2015. Revista de Processo, São Paulo, RT, vol. 268, jun/2017, pp. 71-97, também defendem a possibilidade de realização de audiência de saneamento compartilhado mesmo para causas não complexas, citando entendimento do Fórum Permanente dos Processualistas Civis e do TJMG: "É de se defender também a possibilidade de designação da audiência para a tentativa de saneamento em cooperação mesmo nas hipóteses em que não restar configurada a complexidade das matérias de fato ou de direito, o que poderá ocorrer por decisão das próprias partes por intermédio de negócio jurídico extraprocessual ou endoprocessual, ou por decisão do juiz, de ofício ou a requerimento de uma das partes, motivado pela possibilidade de obter a conciliação entre as partes, ou, ainda, pela postura judicial pautada na primazia da cooperação processual e na condução dialética do procedimento. Nesse sentido, merece destaque o Enunciado 298 
convenção processual para delimitação das questões de fato objeto da atividade probatória e das questões de direito importantes para a decisão de mérito $\left(\$ 2^{\circ}\right) .^{69}$ Noutras palavras, no ambiente do saneamento compartilhado ou cooperativo, abre-se margem para ampla colaboração processual entre partes e juiz ${ }^{70}$ que, na audiência de saneamento, podem ajustar negócios processuais específicos, tais como: delimitação dos fatos objeto da atividade probatória e dos próprios meios de prova que serão utilizados (arts. 357, II, e $\$ 2^{\circ}$, e $139, \mathrm{VI}$ ), com possibilidade de inserção de previsão da distribuição negociada dos ônus probatórios entre as partes (arts. 357 , III, e $373, \mathbb{S} \$ 3^{\circ}$ e $4^{\circ}$ ); houver necessidade de prova pericial, já se poderia também ajustar indicação convencional de perito pelas partes (art. 471), com delineamento de parâmetros para fixação e adiantamento dos honorários periciais e forma de atuação dos assistentes

do Fórum Permanente de Processualistas Civis, sustentando o entendimento consolidado dos processualistas brasileiros quanto à possibilidade de designação da audiência de saneamento mesmo quando inexistir a complexidade prevista no novo regramento processual civil: 'ENUNCIADO 298: (art. 357, $\mathbb{S} 3^{\circ}$ ) A audiência de saneamento e organização do processo em cooperação com as partes poderá ocorrer independentemente de a causa ser complexa (...)'. A possibilidade de designação da audiência mesmo nos casos em que não for evidenciada a complexidade também encontra respaldo no entendimento consolidado pelos julgadores mineiros, a partir da aprovação do Enunciado 29 do Tribunal de Justiça de Minas Gerais, nos seguintes termos: '(art. 357, $\mathbb{S} 3^{\circ}$ ) A audiência de saneamento e organização do processo em cooperação com as partes poderá ocorrer em qualquer tipo de demanda, independentemente de a causa ser complexa, a critério do juiz, visando à autocomposição das partes””.

69 Cf. GOMES, Gustavo Gonçalves. O saneamento cooperativo como roteiro de organização e julgamento do processo. 2016. 326 p. Tese (doutorado em direito). Pontifícia Universidade Católica de São Paulo - PUC-SP, São Paulo/SP, pp. 247 e 252/253. Disponível em: https:// tede2.pucsp.br/bitstream/handle/19546/2/Gustavo\%20Goncalves\%20Gomes.pdf. Acesso em 04/04/2019. Cf. também LIMA, Marcellus Polastri; DIAS, Luciano Souto, Reflexões e proposições sobre a audiência de saneamento compartilhado no Código de Processo Civil de 2015. Revista de Processo, São Paulo, RT, vol. 268, jun/2017, pp. 71-97, que apontam a possibilidade de se ajustar o negócio processual do art. $357, \mathbb{2} 2^{\circ}$, do $\mathrm{CP} / 2015$, antes de eventual audiência de saneamento compartilhado: "De forma a antecipar uma decisão do juiz pelo saneamento unilateral ou compartilhado, as próprias partes terão a faculdade de apresentar ao juiz a delimitação consensual das questões de fato sobre as quais recairá a atividade probatória e das questões de direito relevantes para a decisão de mérito32, o que terá efeito vinculante em relação às partes e ao magistrado, porém a convenção dependerá de homologação pelo juiz (art. 357, $\left.\mathbb{S} 2^{\circ}, \mathrm{CPC} / 2015\right)$. A exigência de homologação decorre da própria atribuição jurisdicional de fiscalizar as questões formais que envolvem o procedimento. $\mathrm{O}$ pacto de delimitação consensual representa um negócio jurídico processual incidental atípico, já que, diferentemente dos negócios jurídicos comuns (art. 190, CPC/2015), que independem de homologação, a delimitação consensual exigirá a manifestação de aquiescência do juiz para que o ato tenha eficácia, o que decorre da natureza das questões que serão objeto da delimitação, as quais envolvem temas alusivos à própria atividade jurisdicional e à relação jurídica processual, extrapolando os interesses particulares das partes"

70 Cf. LIMA, Marcellus Polastri; DIAS, Luciano Souto, Reflexões e proposições sobre a audiência de saneamento compartilhado no Código de Processo Civil de 2015. Revista de Processo, São Paulo, RT, vol. 268, jun/2017, pp. 71-97: "É justamente quanto ao saneamento compartilhado do processo $\left(\mathrm{CPC} / 2015\right.$, art. $357, \mathbb{S} 3^{\circ}$ ) que mais se demonstra a influência do sistema da cooperação processual, com possibilidade de autorregulação das partes, mas com a participação do juiz no ato processual". 
técnicos; bem como ajustar a delimitação das questões de direito a serem tratadas na decisão da causa $\left(\operatorname{art} .357, \mathrm{IV}\right.$, e $\left.\$ 2^{\circ}\right) .^{71}$

Se poderia, também, aproveitar a audiência de saneamento compartilhado para ajustar até mesmo o calendário processual, ${ }^{72}$ não só para a hipótese de prova pericial $\left(\right.$ art. $357, \mathbb{S} 8^{\circ}$ ), mas calendário abrangente, para reger todas as atividades processuais subsequentes ao saneamento, tais como: as demais atividades probatórias, com a sistematização conjunta, por exemplo, da dinâmica da prova pericial com a prova testemunhal, inclusive com previsão da forma de intimação das testemunhas (art. 455), seguido do estabelecimento de limites de páginas para as alegações finais, ${ }^{73} \mathrm{com}$ delimitação das teses

71 Aqui o CP/2015 provavelmente se inspirou diretamente no art. 12 do CPC francês, que tem a seguinte redação: "Art 12. (Loi n 2001022 du 09 avril 2003) Le juge tranche le litige conformément aux règles de droit qui lui sont applicables. Il doit donner ou restituer leur exacte qualification aux faits et actes litigieux sans s"arrêter à la dénomination que les parties en auraient proposé. Tutefois, il ne peut changer la dénomiation ou le fondement juridique lorsque les parties, en vertu d'un accord exprès e pour les droits don elles ont la libre disposition, l'ont lié par qualifications e points de droit auxquels elles entendent limiter le débat". CADIET, Loic. Perspectivas sobre o sistema da justiça civil francesa. São Paulo: Revista dos Tribunais, 2017 , p. 87 , leciona que tal norma admite expressamente que as partes limitem o poder de atuação judicial do ponto de vista jurídico, quanto ao direito aplicável: "Os contratantes podem, contudo, condicionar o poder do juiz quanto aos direitos de livre disposição, prevendo qual a lei que deve ser aplicada no caso. Isso é o que chamamos de acordos de direito aplicável, notadamente ilustrados pelas disposições de electio juris". E mais adiante o mesmo autor, ob. cit., p. 92, apresenta alguns exemplos de acordos deste tipo: "O acordo das partes pode ter por objeto restringir ou ampliar a função do juiz. Em primeiro lugar, restringindo a atuação do juiz, as partes podem encaminhar-lhe 'a qualificação e pontos de direito aos quais querem limitar o debate' (art. 12, alínea 3): por exemplo, debater acerca das indenizações em caso de inexecução de um contrato, mas não sobre a validade desse contrato; discutir as regras de compra e venda, mas não os contratos empresariais; tratar da aplicação da lei argentina em detrimento da lei francesa no caso concreto etc. Em todos os casos descritos, o juiz perde poder, conforme preceitua a alínea 2 do artigo 12, de 'dar ou restituir a qualificação exata dos atos e fatos litigiosos', vale dizer, seu poder de requalificação, assim como sua autoridade para delimitar de ofício as questões de direito (moyens de droit)". Esse parece o sentido do disposto no art. 357, $\$ 2^{\circ}$, do CPC/2015, pois permite que as partes ajustem, em convenção processual, delimitação consensual das questões de direito a serem apreciadas pelo juiz, impondo sua vinculatividade tanto para as partes como para o próprio juiz, quando homologar a convenção, e, com isso, teria o juiz de se ater, no momento da decisão, aos temas de direito delimitados pelas partes, impedindo-se, em tal caso, o exercício do poder de aplicar o direito de ofício ao caso, alterando a qualificação jurídica dada pelas partes (iuria novit curia).

72 NOGUEIRA, Pedro Henrique. Negócios Jurídicos Processuais. $3^{\mathrm{a}}$ ed. Salvador: Editora Jus Podium, 2018, p. 295, aponta, como visto, que o primeiro momento adequado para estabelecer o calendário do processo, é o da audiência prevista no art. 334 do CPC/2015, mas logo a seguir destaca que "nada impede que seja feito em outro momento", e completa: "É possível também estipular um calendário apenas para uma das fases do processo (especialmente a instrução)". Cf. no mesmo sentido CABRAL, Trícia Navarro Xavier. Reflexo das convenções em matéria processual nos atos judiciais. In: CABRAL, Antonio do Passo; NOGUEIRA, Pedro Henrique (Coord). Negócios Processuais. $3^{\text {a }}$ ed. Salvador: Editora Jus Podium, 2017, p. 355: "Contudo, para que a técnica tenha a eficiência esperada, o momento propício para a fixação dos prazos para a prática dos atos processuais é logo no início do processo, ou então ter como termo final para a fixação do calendário o momento da decisão de saneamento e de organização do processo previsto no artigo 357, do NCPC”.

73 Cf. ANDRADE, Érico. A “contratualização” do processo. In: THEODORO JÚNIOR, Humberto (coord.). Processo Civil Brasileiro - novos rumos a partir do CPC/2015. Belo Horizonte: DelRey Editora, 2016, p. 59. 
jurídicas objeto da decisão final (art. 357, $\left.\mathbb{2} 2^{\circ}, \mathrm{CPC} / 2015\right)$ e, por fim, data da decisão, tudo de acordo com as características do caso concreto, para permitir a melhor adequação procedimental em cenário colaborativo entre as partes e juiz, para buscar maior eficiência procedimental, atuando as normas fundamentais lançadas nos arts. $6^{\circ}$ e $8^{\circ}$, do CPC/2015. ${ }^{74}$

Cabe registrar, especialmente em relação ao calendário do processo, a existência de debate na doutrina brasileira se tal figura consistiria ou não em negócio processual e se o juiz integraria ou não tal cenário negocial como parte. ${ }^{75}$

No âmbito do direito francês, é interessante notar que a doutrina parece se encaminhar para a natureza convencional do calendário, ${ }^{76}$ ainda que se entenda

74 CUNHA, Leonardo Carneiro da. A previsão do princípio da eficiência no projeto do novo Código de Processo Civil brasileiro. Revista de Processo, São Paulo, RT, vol. 233, jul/2014, pp. 65-84, delineia o cenário da eficiência no CPC/2015: "No projeto do novo CPC, há também a previsão de acordos de procedimento e o calendário processual, de forma que as partes podem estipular mudanças no procedimento, visando a ajustá-lo às especificidades da causa, bem como convencionar, antes ou durante o processo, sobre seus ônus, poderes, faculdades e deveres processuais. De comum acordo, o juiz e as partes podem fixar, quando for o caso, o calendário para a prática dos atos processuais. É possível, enfim, haver flexibilidade procedimental, com vistas a adoção de regras que garantam maior eficiência para casos que exijam essa flexibilidade. A eficiência funciona como baliza para que haja essa flexibilização procedimental”. E conclui o mesmo autor: "O princípio da eficiência constitui fundamento para a gestão do processo e para a criação de técnicas processuais atípicas, permitindo flexibilização procedimental e justificando os negócios processuais e o calendário processual”.

75 Nesse sentido, DIDIER JR., Fredie, Negócios jurídicos processuais atípicos no CPC-2015. In: CABRAL, Antonio do Passo; NOGUEIRA, Pedro Henrique (Coord). Negócios Processuais. $3^{\mathrm{a}}$ ed. Salvador: Editora Jus Podium, 2017, p. 105, enquadra o calendário no rol dos negócios processuais e a seguir, ob. cit., p. 112, admite que o juiz possa ser parte em convenções processuais. Também CUEVA, Ricardo Villas Bôas. Flexibilização do procedimento e calendário processual no novo CPC. In: CABRAL, Antonio do Passo; NOGUEIRA, Pedro Henrique (Coord). Negócios Processuais. $3^{a}$ ed. Salvador: Editora Jus Podium, 2017, p. 538; e NOGUEIRA, Pedro Henrique. Negócios Jurídicos Processuais. $3^{\mathrm{a}}$ ed. Salvador: Editora Jus Podium, 2018, p. 296, indicam o calendário como negócio processual típico e inserem o juiz com parte do negócio. Já COSTA, Eduardo José da Fonseca. Calendarização processual. In: CABRAL, Antonio do Passo; NOGUEIRA, Pedro Henrique (Coord). Negócios Processuais. $3^{a}$ ed. Salvador: Editora Jus Podium, 2017, p. 519; e YARSHELL, Flávio Luiz, Convenção das partes em matéria processual: rumo a uma nova Era? In: CABRAL, Antonio do Passo; NOGUEIRA, Pedro Henrique (Coord). Negócios Processuais. $3^{\mathrm{a}}$ ed. Salvador: Editora Jus Podium, 2017, p. 91, entendem que o calendário é negócio processual, mas o juiz não o integra, não é parte. Já CABRAL, Antonio do Passo. Convenções Processuais. Salvador: Editora Jus Podium, 2016, p. 70, entende que se trata de ato conjunto, consensual, mas não convencional ou negocial: "Estes atos conjuntos são, portanto, consensuais (baseados na colaboração processual), mas não convencionais. São atos paralelos (ou convergentes) e que se orientam ao mesmo resultado, e talvez por isso sejam confundidos frequentemente com os acordos processuais; mas não são independentes, traduzindo-se em manifestações de vontade distintas e simultâneas (ou sucessivas), e não têm eficácia negocial. (...) No CPC/2015, o calendário do processo (art. 191) e o saneamento compartilhado (art. $357, \mathbb{\$} 3^{\circ}$ ), em nosso modo de ver, também são atos ou requerimentos conjuntos (não acordos). O juiz tem que deferir, autorizar; há um controle judicial prévio e necessário à produção de efeitos. Ou seja, são todas características de atos estimulantes ou postulativos, não dos atos determinantes".

76 AMRANI-MEKKI, Soraya. Le temps et le procès civil. Paris: Dalloz, 2002, p. 284: "Il s'agit de l'établissement d'un calendrier de procédure dénommé contrat du fait qu'il nécessite l'acord des parties ainsi que du juge, qui est partie prenante à cet accord. Il permet d'établir à l'avance le cheminement temporel de l'instance en fixant dès le départ les audiences utiles". Cf. também 
não haver sanções para o descumprimento pelo juiz e mesmo considerando que este não pode negociar suas competências legais, pois o que importa é o destaque do exercício do poder estatal de forma compartilhada e negociada com as partes, em cenário de colaboração, fora da direção processual unilateral, o que seria suficiente para qualificar a figura como negocial ou convencional, ${ }^{77}$ apesar da dificuldade de se enquadrar tais convenções no âmbito do modelo contratual clássico. ${ }^{78}$

CADIET, Loic. Perspectivas sobre o sistema da justiça francesa - seis lições brasileira. São Paulo: Revista dos Tribunais, 2017, p. 97: "Em matéria de acordo processual, tem-se que a decisão do juiz pode estar subordinada ao acordo das partes, o que ocorre quanto o juiz é quem inicia o acordo, por exemplo, ao fixar os prazos procedimentais. O rol de assuntos que será debatido em audiências pode ser objeto de acordo entre as partes. Nesse caso, o juiz é necessariamente parte na convenção, uma vez que a fixação de prazos procedimentais é ofício que lhe incumbe a lei. $\mathrm{O}$ mesmo acordo entre juiz e partes deve aparecer em tudo o que toca às convenções de procedimento, as quais se ocupam da determinação do calendário procedimental estipulado de comum acordo entre as partes e o juiz".

77 AMRANI-MEKKI, Soraya. Le temps et le procès civil. Paris: Dalloz, 2002, p. 285/286, aponta os problemas que a natureza contratual de tais ajustes, como o calendário processual, têm colocado, pois parecem ser desprovidos de força obrigatória e, além do mais, o juiz não poderia negociar seus poderes extraídos da lei, mas, em seguida, a autora apresenta seu entendimento, no sentido de que a base negocial para ajustar o calendário é suficiente para sustentar sua natureza contratual: "La nature de ce contrat de procédure pose problème. La notion de contrat ne se réduit pas à celle d'un accord de volontés. Le contrat est également défini par ses effets car il est consacré par le Droit objectif qui lui donne force obligatoire. Or, force est de constater que le contrat de procédure semble em être dépourvu. (...) Il est encore opposé le fait que le juge tirant son pouvoir de la loi (art. 3 N.C.P.C.) il ne pourrait être objet de négociation. Cependente, il ne renonce pas à ses pouvoirs, au contraire, il les utilise plus intelligemment. Il est possibile d'y voir un contrat en considérant le contrat, non plus comme une notion fonctionnelle, mais comme un mécanisme. Il y a contrat dès lors qul'il y a un mécanisme contractuel d'élaboration d'un acte: la négociation. La force obligatoire n'est plus un élément constitutif".

78 CADIET, Loic. Les conventios relatives au procès en droit français. Sur la contractualisation du règlement des litiges. Quaderni della Rivista di Diritto e Procedura Civile, n. 11, Accordi di parte e processo. Milano, Giuffrè, 2008, p. 31/33: "Les formes de la contractualisation sont donc multiples et d'une grande diversité, qui peut dérouter le civiliste classique. Si certaines de ces formes sont en effet parfaitement réductibles aux catégories traditionnelles du droit civil des contrats, qu'il s'agisse des clauses de différend, de la transaction ou du compromis d'arbitrage, l'assimilation est beaucoup mons èvidente pour d'autres figures de la contractualisation du procès ; tel est en particulier le cas de toutes les formes d'actes de procédure présentant un caractère conventionnel comme la requête conjointe, le contra judiciaire et autres conventions d'administration processuelle. Et le lien entre contrat et contractualisation atteint même son point maximum de distension avec les forme conventionnelles qu'emprunte l'action administrative en matière d'accès au droit, de gestion des procédures et de management des juridictions. La contractualisation repose ainsi sur des usages dégradés ou métaphorique de la notion de contrat, car, en vérité, elle consiste surtout dans l'emploi d'une certaine procédure d'élaboration des normes, règles et décisions, de type contractuel en ce qu'elle fait appel à des phénomènes de participation des parties concernées, tantôt simple adhésion, tantôt véritable négociation, contrahere plutôt que contractus". No mesmo sentido, cf. mais recentemente CADIET, Loic, La qualification juridique des accords processuels. In: CABRAL, Antonio do Passo; NOGUEIRA, Pedro Henrique (Coord). Negócios Processuais. $3^{\mathrm{a}}$ ed. Salvador: Editora Jus Podium, 2017, p. 133/134: "Ces accords, présentés comme des conventions, voire des contrats au regard du droit processuel, le sont-il vraiment au sens du droit des contrats? Losrque la doctrine processualiste parle du contrat judiciaire, l'expression doit-elle être prise au pied de la lettre contractuelle ou n'est-elle qu'une image commode comme le langage juridique en véhicule bien d'autres? (...) Ce n'est pas parce que ces accords n'ont pas les honneurs de la doctrine contractualiste qu'ils ne sont pas des conventions. La particularité de leur objet ou, 
Todavia, tal debate não interfere na perspectiva de que o calendário (ou outras técnicas, como o saneamento compartilhado), enquadrável ou não na figura dos negócios processuais, se apresenta como importante ferramenta colaborativa para a gestão processual, compartilhada entre o juiz e as partes, com possibilidade de adaptação da condução procedimental às peculiaridades do caso concreto, substituindo a tradicional atuação judicial unilateral na condução procedimental. ${ }^{79}$ Noutras palavras, independentemente da discussão em torno da qualificação jurídico-processual do calendário processual, o que importa é aproveitar ao máximo as potencialidades da ferramenta para a boa gestão processual colaborativa.

\section{BREVES INDICAÇÕES CONCLUSIVAS}

O direito processual brasileiro, no contexto do CPC/2015, se alinha com as mais modernas e inovativas técnicas encontradas no cenário comparado, no sentido da implementação da gestão processual flexível e proporcional, a cargo do juiz, para melhor aplicação dos recursos judiciais na busca de maior eficiência possível do sistema jurisdicional para a solução das crises de direito material, mas gestão processual que deve ser implementada pelo juiz em colaboração com as partes, e não mais unilateralmente, inclusive com o uso das importantes ferramentas inseridas no ambiente negociado entre partes e juiz do calendário do processo (art. 191) e do saneamento compartilhado (art. $357, \mathbb{S} \$ 2^{\circ}$ e $3^{\circ}$ ).

Cabe, agora, o estudo e amadurecimento de tais técnicas inseridas no CPC/2015, para aplicação adequada e corrente aos processos que venham adentrar o sistema de justiça estatal, de modo a conferir a devida efetividade ao novo cenário normativo, buscando, com isso, a estruturação de um processo civil inovativo na prática judicial, impedindo-o que essas importantes diretrizes se tornem "letra morta" ou apenas uma utopia legislativa. ${ }^{80}$

plus généralement, de leur environnement peut simplement expliquer le désintérêt manifesté à leur égard par les espécialistes du droit des contrats. (...) Les accords processuels sont bien des accords de volonté et ces accords sont bien destinés à produire um effet sur l'ordonnancement juridique du procès, effet de droit, assurément. Le fait que des accords processuels soient parfois subordonnés à l'intervention du juge n'est pas davantage de nature à les priver de leur nature conventionnelle".

79 CADIET, Loic, La qualification juridique des accords processuels. In: CABRAL, Antonio do Passo; NOGUEIRA, Pedro Henrique (Coord). Negócios Processuais. $3^{\mathrm{a}}$ ed. Salvador: Editora Jus Podium, 2017, p. 137: "Le plus important n'est-il pas de constater que la juridcition peut être l'objet de conventions particulières associant ainsi les parties à la réalisation de l'oeuvre de justice que le juge a mission institutionnelle d'assurer. Il faut se féliciter de cette coopération si caractéristique de la procédure civile contemporaine qui renvoie, dos à dos, conception accusatoire et conception inquisitoire du procès civil. Les accords processuels témoignent exemplairement que le procès n'est pas plus l'oeuvre exclusive du juge que le contrat n'est pas l'oeuvre exclusive des parties. À bien des égards, la procédure devant les juridictions étatiques emprunte ainsi des solutions traditionnelles de la procédure arbitrale. Ici comme là, c'est un modèle du procès coopératif qui tend à se développer".

80 LUPOI, Michele Angelo. Tra flessibilità e semplificazione - Un embrione di case management all'italiana? Bologna: Bononia University Press, 2018, p. 596: "Tutti questi nuovi strumenti, 
A operacionalização das novas técnicas inseridas no CPC/2015, especialmente aquelas colaborativas, por importarem em mudança no paradigma da atuação jurisdicional baseada na condução processual unilateral pelo juiz, vai exigir até mesmo transformações culturais, e por isso é necessário sua adequada inserção no ambiente universitário de formação dos profissionais que atuam na esfera jurídico-processual, ${ }^{81}$ tudo para buscar a atuação judicial mais simplificada e mais próxima da sociedade, ${ }^{82}$ ou seja, mais aberta ao diálogo e à cooperação entre os atores processuais, ${ }^{83}$ na linha inserida no CPC/2015 no âmbito da adoção explícita do princípio da colaboração e da ampla admissão dos negócios processuais típicos e atípicos, como importante ferramenta para implementação das diretrizes da gestão processual flexível, proporcional e colaborativa, inseridas nas normas fundamentais do novo Código (arts. $4^{\circ}, 6$ e $8^{\circ}$ ).

peraltro, per quanto il loro uso possa essere implementato dal legislatore a vari livelli (...), rischiano di restare lettera morta nella prassi o comunque di essere confinati alle pratiche virtuose di alcuni uffici giudiziari se non di singoli giudici volenterosi. (...) Per potere imprimere un cambiamto rispetto al desolante panorama della giustizia civile contemporanea e per disegnare un modello processuale davvero innovativo, d'altro canto, tali strumenti dovrebbero avere un'applicazione capillare. Allo stato, questa prospettiva pare però un'utopia”.

81 BREGGIA, Luciana. La giustizia del XXI secolo dentro e fuori la giurisdizione: uyna riflessione sul principio di effettività. Rivista Trimestrale di Diritto e Procedura Civile, Milano, Giuffrè Editore, v. LXX, 2016, n. 2, p. 736. Cf. também LUPOI, Michele Angelo. Tra flessibilità e semplificazione - Un embrione di case management all'italiana? Bologna: Bononia University Press, 2018, p. 635: "In questo tribolato momento storico, d'altro canto, si avverte la necessità di un cambiamento culturale che riavvicini i cittadini all'amministrazione della giustizia, faccia riconquistare alla magistratura la fiducia perduta, responsabilizzi gli avvocati facendoli partecipare in chiave non oppositiva ma collaborativa alla conduzione del processo".

82 É o que BREGGIA, Luciana. La giustizia del XXI secolo dentro e fuori la giurisdizione: uyna riflessione sul principio di effettività. Rivista Trimestrale di Diritto e Procedura Civile, Milano, Giuffrè Editore, v. LXX, 2016, n. 2, p. 735, denominou de atuação reflexiva da jurisdição: "Un pensiero che, mi pare, possa riguardare anche la giurisdizione: la categoria della riflessività in tal caso indica che se la giurisdizione riflette la società, la conosce, allora a sua volta la società riflette e conosce la giurisdizione. Questo presuppone un'organizzazione giudiziaria comprensibile, semplificata nei riti e nelle competenze: non solo il diritto, ma anche la giurisdizione deve entrare in comunicazione con i sistemi sociali, per rendere trasparente l'attività dei giudici, le politiche giudiziarie avviate, pemettere l'informazione e la formazione reciproca. La riflessività in realtà è alla base di tutte le pratiche partecipative e cooperative e in generale dei modi amichevoli di soluzioni delle liti dove le persone decidono di osservare le regole non per timore di eventuali sanzioni, ma perché, avendo preso parte ai momenti formativi, riconoscono in esse quei valori che costituiscono la loro essenza ed identità”.

83 CADIET, Loic. Les conventios relatives au procès en droit français. Sur la contractualisation du règlement des litiges. Quaderni della Rivista di Diritto e Procedura Civile, n. 11, Accordi di parte e processo, Milano, Giuffrè, 2008, p. 35: "Favoriser la contractualisation de la justice aux conditions que je viens d'indiquer, c'est simplement contribuer à faciliter l'acceptation sociale de l'activité juridictionnelle ; c'est donc contribuer à retisser du lien social et, lorsque ces modes se développent au sein même de l'institution judiciaire, c'est promouvoir une justice plus citoyenne, une justice plus démocratique, sous la tutelle d'un Etat modérateur en charge des èquilibres sociaux, qu'on pourrait appeler l'Etat-médiateur, après l'Etat-genderme du 19 ème siècle et l'Etat-providence du $20^{\text {ème }}$ siècle". 


\section{REFERÊNCIAS}

ABBOUD, Georges; LUNELLI, Guilherme. Ativismo judicial e instrumentalidade do processo - diálogos entre discricionariedade e democracia. Revista de Processo, São Paulo, RT, vol. 242, pp. 21-47, abr/2015.

AMRANI-MEKKI, Soraya. Le temps et le procès civil. Paris: Dalloz, 2002.

ANDRADE, Érico. As novas perspectivas do gerenciamento e da “contratualização" do processo. Revista de Processo, São Paulo, RT, ano 35, n. 193, pp. 167-199, mar/2011.

BATISTA JÚNIOR, Onofre Alves; CASTRO, Sérgio Pessoa de Paula (Coord.). Tendências e Perspectivas do Direito Administrativo: uma visão da escola mineira. Belo Horizonte, Ed. Fórum, 2012, pp. 31-58.

BIAVATI, Paolo. Osservazioni sulla ragionevole durata del processo di cognizione. Rivista Trimestrale di Diritto e Procedura Civile. Milano, Giuffrè Editore, v. LXVI, n. 2, pp. 475-490. giugno/2012.

BIAVATI, Paolo. Il linguaggio degli atti giudiziari. Rivista Trimestrale di Diritto e Procedura Civile. Milano, Giuffrè Editore, v. LXXI, n. 2, pp. 467-483, giugno/2017.

BREGGIA, Luciana. La giustizia del XXI secolo dentro e fuori la giurisdizione: uyna riflessione sul principio di effettività. Rivista Trimestrale di Diritto e Procedura Civile. Milano, Giuffrè Editore, v. LXX, n. 2, pp. 715-736, giugno/2016.

BRITO, Rita. (Coord.). Novos Rumos da Justiça Cível: Conferência Internacional, Lisboa, abril 2008. Coimbra: Cejur-Coimbra Editora, 2009.

CABRAL, Antonio do Passo; NOGUEIRA, Pedro Henrique (Coord). Negócios Processuais. $3^{\mathrm{a}}$ ed. Salvador: Editora Jus Podium, 2017.

CABRAL, Antonio do Passo. Convenções Processuais. Salvador: Editora Jus Podium, 2016.

CADIET, Loic. Perspectivas sobre o sistema da justiça francesa - seis lições brasileira. São Paulo: Revista dos Tribunais, 2017.

CADIET, Loïc. Les conventios relatives au procès en droit français. Sur la contractualisation du règlement des litiges. Quaderni della Rivista di Diritto e Procedura Civile, n. 11. Accordi di parte e processo. Milano, Giuffrè, 2008.

CADIET, Loïc; JEULAND, Emmanuel. Droit judiciaire privé. 5 ed. Paris: LexisNexis, 2006.

CANELLA, Maria Giulia. Gli accordi processuali francesi volti alla "regolamentazione collettiva" del processo civile. Rivista Trimestrale di Diritto 
e Procedura Civile. Milano, Giuffrè, anno LXIV, n. 2, pp. 549-580, giugno/2010.

CAPONI, Remo. Il principio di proporzionalità nella giustizia civile: prime note sistematiche. Rivista Trimestrale di Diritto e Procedura Civile. Milano, Giuffrè Editore, v. LXV, n. 2, pp. 389-406, giugno/2011.

CAPPONI, Bruno. Sulla "ragionevole brevità" degli atti processuali civili. Rivista Trimestrale di Diritto e Procedura Civile. Milano, Giuffrè Editore, v. LXVIII, n. 3, pp. 1075-1091, settembre/2014.

CAVALLONE, Bruno. In difesa della veriphobia. Rivista di Diritto Processuale, Padova: Cedam, anno LXV, n. 1, pp. 1-26, gennaio-febbraio/12010.

CUNHA, Leonardo Carneiro da. A previsão do princípio da eficiência no projeto do novo Código de Processo Civil brasileiro. Revista de Processo, São Paulo, RT, vol. 233, pp. 65-84, jul/2014.

DE CRISTOFARO, Marco. Case management e riforma del processo civile, tra effettività della giurisdizione e diritto costituzionale al giusto processo. Rivista di Diritto Processuale, Padova, Cedam, anno LXV, n. 2, pp. 282-305, marzoaprile/2010.

DIDIER JR., Fredie; CABRAL, Antônio do Passo; CUNHA, Leonardo Carneiro da. Por uma nova teoria dos procedimentos especiais - dos procedimentos às técnicas. Salvador: Editora JusPodium, 2018.

FINOCCHIARO, Giusepe. Il principio di sinteticità nel processo civile. Rivista di Diritto Processuale. Padova: Cedam, anno LXVIII, ns. 4-5, pp. 853-869, luglio-oattobre/2013.

GAJARDONI, Fernando da Fonseca. Flexibilização procedimental: um novo enfoque para o estudo do procedimento em matéria procedimental. São Paulo: Atlas, 2008.

GOMES, Gustavo Gonçalves. O saneamento cooperativo como roteiro de organização e julgamento do processo. 2016. 326 p. Tese (doutorado em direito). Pontifícia Universidade Católica de São Paulo - PUC-SP, São Paulo/SP.

GUSTIN, Miracy B. S.; e DIAS, Maria Tereza Fonseca. (Re)pensando a Pesquisa Jurídica. $4^{\mathrm{a}}$ ed. Belo Horizonte: Editora DelRey, 2015.

HOFFMAN, Paulo. Saneamento Compartilhado. São Paulo: Quartier Latin, 2011.

LIMA, Marcellus Polastri; DIAS, Luciano Souto, Reflexões e proposições sobre a audiência de saneamento compartilhado no Código de Processo Civil de 2015. Revista de Processo, São Paulo, RT, vol. 268, pp. 71-97, jun/2017.

LOPES, Maria Elizabeth de Castro. Ativismo judicial e novo Código de Processo Civil. Revista de Processo, São Paulo, RT, vol. 205, pp. 301-306, mar/2012. 
LUPOI, Michele Angelo. Tra flessibilità e semplificazione - Un embrione di case management all'italiana? Bologna: Bononia University Press, 2018.

MORAES, Guilherme Peña de (Org.). 30 Anos da Constituição Federal e o Direito Brasileiro. Rio de Janeiro: Forense-Gen, 2018.

MOTTA, Francisco José Borges; TASSINARI, Clarissa. Ativismo judicial e decisões por princípio: uma proposta de fixação dos limites da atuação do Poder Judiciário. Revista de Processo, São Paulo, RT, vol. 283, pp. 481-499, set/2018.

NOGUEIRA, Pedro Henrique. Negócios Jurídicos Processuais. $3^{a}$ ed. Salvador: Editora Jus Podium, 2018.

OLIVEIRA, Carlos Alberto Álvaro de. Efetividade e processo de conhecimento. Revista de Processo, São Paulo, RT, vol. 96, pp. 59-69, out-dez/1999.

PICOZZA, Elisa. Il calendario del processo. Rivista di Diritto Processuale, Padova, Cedam, anno LXIV, n. 6, pp. 1650-1659, novembre-dicembre/2009.

TARUFFO, Michele. Note sintetiche sulla sinteticità. Rivista Trimestrale di Diritto e Procedura Civile. Milano, Giuffrè Editore, v. LXXI, n. 2, pp. 453-466, giugno/ 2017.

THEODORO JÚNIOR, Humberto. Curso de Direito Processual Civil. $56^{a}$ ed. Rio de Janeiro: Gen-Forense, 2015, vol. I.

THEODORO JÚNIOR, Humberto (coord.). Processo Civil Brasileiro - novos rumos a partir do CPC/2015. Belo Horizonte: DelRey Editora, 2016.

WAMBIER, Luiz Rodrigues, A audiência preliminar como fator de otimização do processo. O saneamento "compartilhado" e a probabilidade de redução da atividade recursal das partes. Revista de Processo, São Paulo, RT, vol. 118, pp. 137-142, nov/dez 2004.

ZUFELATO, Camilo; BONATO, Giovanni; SICA; Heitor Vitor Mendonça; CINTRA, Lia Carolina Batista. I Colóquio Brasil-Itália de Direito Processual Civil. Salvador: Editora Jus Podium, 2016.

Recebido em: 15/04/2019. Aprovado em: 11/09/2019. 